\title{
Anomalous Sea Surface Temperatures and Local Air-Sea Energy Exchange on Intraannual Timescales in the Northeastern Subtropical Pacific*
}

\author{
R. E. Ronca And D. S. BAtTisti \\ Department of Atmospheric Sciences, University of Washington, Seattle, Washington
}

(Manuscript received 19 December 1995, in final form 10 June 1996)

\begin{abstract}
Here 11 years of surface data (1961-72, excluding 1963) taken at ocean weather ship N (OWS N) are analyzed. OWS $\mathrm{N}$ is located in the subtropical eastern Pacific Ocean $\left(140^{\circ} \mathrm{W}, 30^{\circ} \mathrm{N}\right)$. Bulk formulas are employed to calculate each component of the surface heat flux (sensible, latent, longwave, and shortwave) from the 3-h measurements of sea surface temperature (SST), air temperature, surface humidity, wind speed, and cloudiness. Analyses are performed on fluxes averaged over daily and monthly intervals. Results indicate a large fraction of the variance in net surface energy flux is associated with anomalies in the latent heat flux; the latter are principally due to variability in the surface wind speed. Cross correlation and regression analyses of monthly anomalies of SST and SST tendency ( $\partial \mathrm{SST} / \partial t)$ with the surface heat flux components indicate over $50 \%$ of the variance in SST-tendency anomalies is accounted for by local anomalies in the net surface energy flux.

In the summer, the summed variance in the four components of the surface heat flux is explained almost completely by two modes of variability that are nearly orthogonal. The first (second) mode is defined as the combination of surface flux components that optimally covaries with the SST-tendency anomaly (SST anomaly) and it contains $74 \%$ (26\%) of the summed variance in all of the surface heat flux components. In addition, the net heat flux anomaly associated with the the SST-tendency anomaly, which results from the summing of the individual components that define the first mode, accounts for virtually all $(96 \%)$ of the variance in the net surface flux; it is dominated by the latent heat flux component. The second mode is dominated by the variability in the shortwave flux (mainly due to changes in the cloudiness), but the opposing anomalies in latent and longwave flux largely cancel the anomalies in the shortwave. Hence, the net heat flux associated with the flux components that covary with the SST anomalies is too small to generate significant variability in SST.

The physical scenario consistent with the analyses presented is as follows. Throughout the year, variability that is inherent to the atmosphere causes net surface flux anomalies (mainly due to anomalies in evaporation driven by wind speed anomalies) that account for over $50 \%$ of the variability in SST. During the summer months, the changes in the SST that are driven by the aforementioned atmospheric variability, in turn, force changes in the lower troposphere (e.g., in the low-level cloudiness) that are announced by a redistribution of the surface heat flux components, though these changes in the lower atmosphere do not further affect the ocean because there is an insignificant change in the net surface heat flux.

The results obtained from the observations are confirmed using a one-dimensional ocean mixed layer model. Model results also indicate that heat flux anomalies due to entrainment processes act in the same sense as the net surface heat flux anomalies but are small (about 7\% of the variance) compared to the surface heat flux anomalies. Anomalies in ocean advection contribute significantly to SST anomalies only during late wintertime and only for seasonally averaged and longer timescales.
\end{abstract}

\section{Introduction}

Sea surface temperature (SST) is an important variable in the description of the marine climate. The energy transferred between the ocean and the atmosphere is to a large extent dependent on SST; the sensible heat flux, latent heat flux, and longwave radiative flux at the sur-

\footnotetext{
* Joint Institute for the Study of the Atmosphere and Oceans (JISAO) Contribution Number 344.

Corresponding author address: Dr. David S. Battisti, Department of Atmospheric Sciences, AK-40, University of Washington, Box 351640, Seattle, WA 98195.
}

face all are functions of SST. Furthermore, in the subtropical and midlatitude regions marine stratiform cloudiness (MSC) ${ }^{1}$ and SST are known to be significantly negatively correlated in the summer (Klein and Hartmann 1993; Norris and Leovy 1994; Weare 1994; Klein et al. 1995).

Lead-lag analyses (e.g., Davis 1976; Wallace and Jiang 1987) and modeling studies (e.g., Miller 1992; Alexander 1992) have shown that in the midlatitudes the atmosphere tends to drive SST variability. However, SST in turn affects the near surface air and perhaps the

\footnotetext{
${ }^{1}$ Norris and Leovy (1994) define MSC to be stratocumulus, stratus and sky-obscuring fog.
} 
atmospheric circulation (e.g., Lau and Nath 1990; Wallace et al. 1990; Kushnir and Lau 1992; Peng et al. 1995; Barsugli 1995). For example, air-sea feedback between cloudiness and SST is likely in the midlatitude during summer when marine stratiform clouds are common. Here the static stability of the lower troposphere is strongly related to MSC (Klein and Hartmann 1993). Since the surface air temperature closely follows the SST, a decrease in SST increases the static stability of the lower troposphere. This argument suggests that the significant negative correlations between summertime anomalies in marine stratus clouds and SST (Klein and Hartmann 1993; Norris and Leovy 1994; Weare 1994; Klein et al. 1995) are due to the forcing of the atmosphere by the ocean. On the other hand, increased MSC corresponds to decreased solar radiation at the surface that may lead to negative SST anomalies. Thus the cause of the negative correlation between anomalous midlatitude and subtropical summertime cloudiness and SST anomalies is not clear; the correlation may indicate a direct (one-way) forcing of the atmosphere by the ocean or that variability is inherently due to the feedbacks between the atmosphere and ocean.

SST anomalies may result from variability in horizontal currents and vertical motions, surface energy fluxes (sensible and latent heat flux, solar heat flux, infrared radiation), diffusion, and vertical turbulent mixing. Several studies have shown that anomalous local surface energy fluxes and entrainment of water from below the thermocline into the surface layer are the most important processes in midlatitude SST anomaly formation and maintenance (Clark 1972; Gill and Niiler 1983; Frankignoul and Reynolds 1983; Frankignoul 1985; Haney 1985; Luksch and Storch 1992; Alexander and Deser 1995; Delworth 1996; Battisti et al. 1995). Thus, in the extratropics, vertical rather than horizontal processes appear to dominate the development of SST anomalies [notable exceptions are found in localized, strong western boundary current regions (see, e.g., Haney 1985; Luksch and Storch 1992; Battisti et al. 1995) where horizontal advection is important to the evolution of SST].

Energy exchange between the atmosphere and ocean has a seasonal dependence. For example, the correlations between anomalies in SST and MSC in the subtropics and midlatitudes are most significant in the summer months. If these correlations are due to the response of the atmosphere to SST variability, it suggests that the anomalous forcing of the lower troposphere by the ocean is significant during the summer. Furthermore, Cayan (1992) found the correlations between anomalous latent and sensible heat fluxes and $\partial \mathrm{SST}^{\prime} / \partial t$ are largest in the winter months, suggesting that the air-sea energy fluxes force the evolution of SST anomalies more strongly in the winter than in the summer. Thus, in the midlatitude oceans, the air-sea energy exchange and processes that cause the formation, maintenance, and decay of SST anomalies may be quite different in summer than in winter.

The goal of this study is to gain some insight into the processes controlling the anomalies in the local airsea interaction at ocean weather ship $\mathrm{N}$ (hereafter OWS $\mathrm{N})$, located away from any major oceanic currents and within the climatological subtropical high pressure in the eastern Pacific. The climate at OWS $\mathrm{N}$ is characterized by summertime marine stratus clouds that form under the trade inversion and occasional wintertime storms. OWS $\mathrm{N}$ was chosen in part because of the possibility of determining the processes that govern the observed relationship between anomalies in marine stratus clouds and SST. The analysis is designed to answer the following questions:

- What processes dominate the anomalous air-sea exchange and how do their relative magnitudes change with season?

- Can processes by which the atmosphere drives the ocean and processes by which the ocean drives the atmosphere be distinguished?

- To what extent can the flux of energy across the airsea interface explain the observed SST anomalies on monthly to seasonal timescales?

\section{Data and energy flux parameterizations}

The measured variables at OWS $\mathrm{N}$ used in this study are wind speed and direction, air temperature, dewpoint temperature, cloud type and amount (in oktas of sky cover), SST, and upper-ocean temperature data (in 5-m increments). Air temperature and dewpoint were measured with a sling psychrometer on the deck of the ship at a height of about $10 \mathrm{~m}$ above the mean sea level, SST was measured with a bucket and mercury thermometer, and wind speed and direction were measured by a propeller-anemometer-wind-vane combination located at a height of about $25 \mathrm{~m}$ above mean sea level (Dorman et al. 1974). The temperature of the ocean below the surface was determined with bathythermographs and hydrocast observations (Dorman et al. 1974).

The data were taken in three-hour increments. For this study, all data are averaged over 24 hours, except cloud amount, which is divided into daytime (0600 to 1800 LT) cloud amount and total (24-h) cloud amount. The value of the daytime cloud amount is used in the estimate of the solar forcing at the surface. Days for which data are missing are filled in with climatological values. The daily climatology, denoted by $\{\cdot\}$, is calculated by making a 365 -day cubic spline from the averages of each month of the year.

The measurements taken at OWS $\mathrm{N}$ have errors associated with them. For example, air temperature measurements made on-board ships have systematic errors associated with the solar heating of the deck of the ship (see, e.g., Goerss and Duchon 1980). At OWS N, this error causes the diurnal cycle in air temperature recorded 


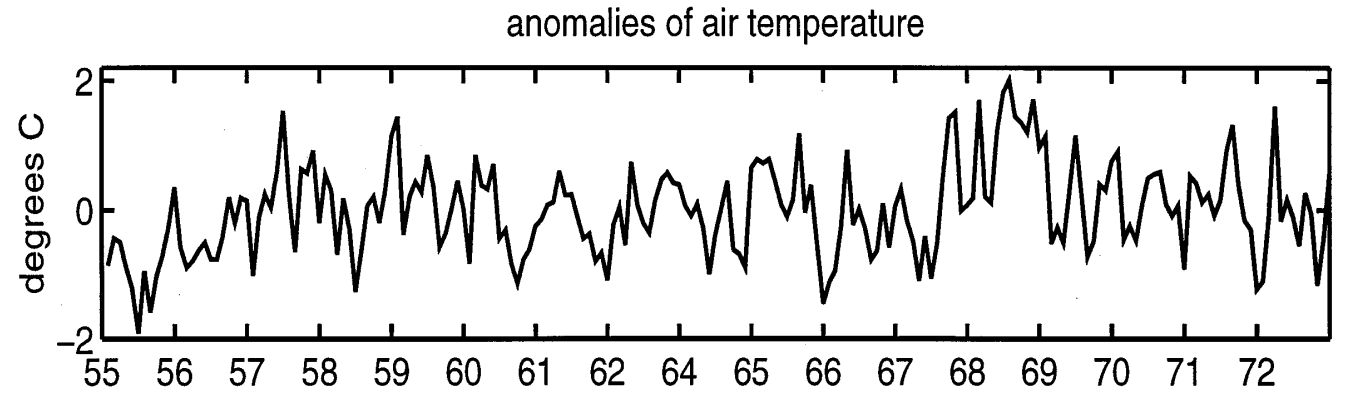

anomalies of sea surface temperature

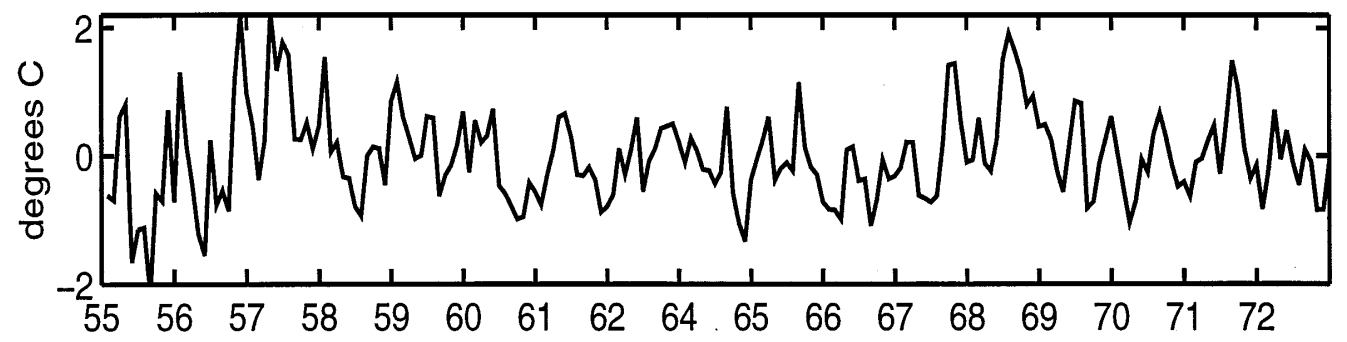

anomalies of SST-Tair

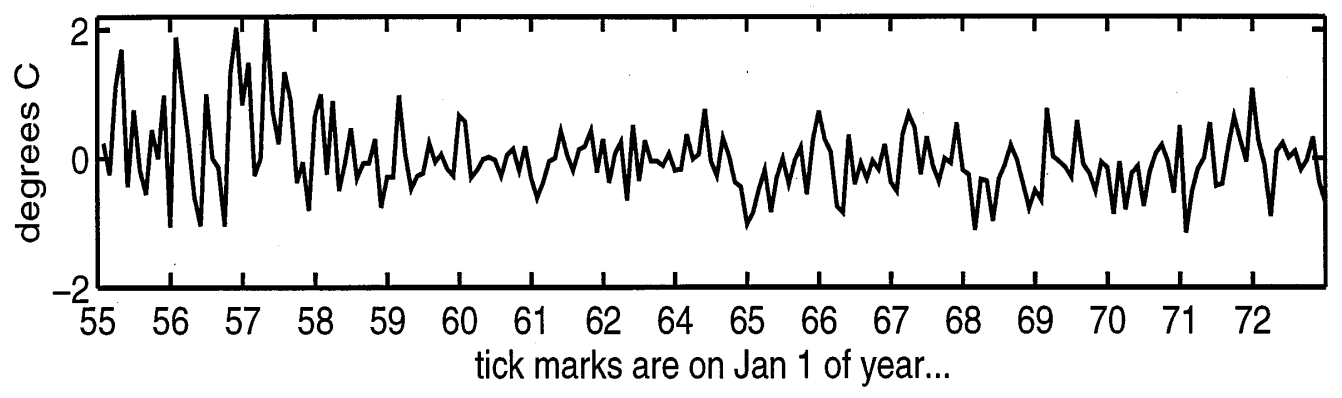

FIG. 1. Monthly anomalies in air temperature $\left(T_{\text {air }}^{\prime}\right)$, sea surface temperature $\left(\mathrm{SST}^{\prime}\right)$, and the air-sea temperature difference $\left(\mathrm{SST}^{\prime}-T_{\text {air }}^{\prime}\right.$ ) at OWS $\mathrm{N}$ for the years 1955-72, except year 1963.

at OWS $\mathrm{N}$ to be enhanced by less than $0.5^{\circ} \mathrm{C}$ compared to the diurnal cycle measured by a buoy at the same latitude (M. Rozendaal, 1995 personal communication). Sarachik (1984) estimated the random errors in measurements of air temperature, SST, and dewpoint to be $1{ }^{\circ} \mathrm{C}$; for wind speed the random error is estimated to be $2 \mathrm{~m} \mathrm{~s}^{-1}$, and for total cloudiness it is $20 \%$ cloud cover.

Measurements at OWS $\mathrm{N}$ were made at the same location $\left(140^{\circ} \mathrm{W}, 30^{\circ} \mathrm{N}\right)$ from $1946-72$. There were many days when data were not collected in years prior to 1955 , so those years are excluded from this analysis. Data from the year 1963 are excluded because the recorded measurements of cloud amount are inconsistent: the total cloud amount during that year was sometimes recorded as less than the stratus cloud amount.

The monthly anomalies of air temperature $\left(T_{\text {air }}\right), \mathrm{SST}$, and their difference $\left(\mathrm{SST}^{\prime}-T_{\text {air }}^{\prime}\right.$ ) are shown in Fig. 1. Monthly anomalies are calculated by subtracting the mean of each particular month from the month-averaged data, and are denoted with a prime $\left(^{\prime}\right)$ throughout the paper. The standard deviation of the measured $\mathrm{SST}^{\prime}-$ $T_{\text {air }}^{\prime}$ is greatest in the years 1955-58, decreases in the years 1958-62, and increases in the years 1964-72. The estimate of the air-sea energy flux depends strongly on the air-sea temperature difference: Dorman et al. (1974) noted that the annual cycle of the air-sea energy flux at OWS $\mathrm{N}$ for the period 1954-60 is distinctly different from the period 1961-72. Whether or not this difference is real or is due to measurement differences has not been investigated in this study. To avoid this issue, only the 11 years 1961-72 (excluding 1963, as mentioned in the previous paragraph) of daily data are used in the following analyses. The primary results from this study remain unchanged when the $17-y r$ dataset is used; the years 1955-60 are used to test the reproducibility of some of the statistical results presented (see also Ronca 1995). 
The surface energy fluxes and their abbreviations are solar (or shortwave) $\left(Q_{s w}\right)$, net infrared (or longwave) $\left(Q_{l w}\right)$, latent, and sensible $\left(Q_{l h}\right.$ and $Q_{s h}$, respectively). Surface solar heating is estimated using the empirical formula from Reed (1977). The net downward longwave flux is estimated using the formula from Isemer and Hasse (1987). Latent and sensible heat fluxes are estimated using the bulk formula transfer coefficients and are from Isemer and Hasse (1987). All fluxes used in this study are calculated using daily averages of the observed variables, except for solar flux, which is calculated using the daytime (0600 to 1800 LT) cloudamount averages. Throughout this paper, the convention is that positive fluxes warm the ocean. For example, a positive latent heat flux anomaly indicates an anomalous decrease in net evaporation.

The errors and biases of each of the parameterizations that relate the field variables to the energy fluxes are discussed in Weare (1989). These errors, however, probably do not affect the results qualitatively because they are unlikely to cause a change in the relative phases or spectral characteristics of the surface energy fluxes. ${ }^{2}$ Thus, the parameterizations are useful for gaining an understanding of the gross features of the energy balance at the air-sea interface and the relationship between the SST anomalies and the surface energy flux anomalies.

\section{Analysis of air-sea energy fluxes at OWS $\mathbf{N}$}

\section{a. The dominant surface energy fluxes at OWS $N$}

The variances of the monthly anomalies in the four surface fluxes are shown in the penultimate right hand column of Table 1 . The component of the heat flux anomaly that displays the greatest variance is the latent heat flux anomaly. The variance in the monthly mean anomaly of the latent heat flux is greater than the other three components annually, as well as during the "summer" (JJASO) and "winter" (DJFMA) seasons. ${ }^{3}$ Second in magnitude to the latent heat flux anomaly is the surface solar flux anomaly.

The correlation coefficients among the four surface energy fluxes are shown in Table 1. The majority of correlation coefficients that are significantly different from zero are positive; they indicate that, in general, the surface flux anomalies all act either to cool the ocean or to warm the ocean. A notable exception is for the longwave and solar energy flux anomalies,

\footnotetext{
${ }^{2}$ We also calculated solar fluxes using the formula of Smith and Dobson (1984), and the turbulent fluxes using bulk formulas from both Large and Pond (1982) and Liu et al. (1979). The relationships between the anomalous heat fluxes, $\mathrm{SST}^{\prime}$ and $\partial \mathrm{SST}^{\prime} / \partial t$ reported in section 3 are insensitive to the choice of flux parameterization.

${ }^{3}$ Summer and winter seasons are defined by the distinctly different relationships and magnitudes of the energy fluxes during the months of June through October and December through April, respectively.
}

which are negatively correlated annually and during both seasons. The solar energy flux and longwave parameterizations both depend on the cloud amount but in the opposite sense, therefore their negative correlation is expected.

The monthly anomalies in sensible and latent heat flux are strongly correlated annually and over each season. This is to be expected because the parameterization for both these fluxes depends on wind speed. Furthermore, sensible heat flux depends on the air-sea temperature difference, and latent heat flux depends on the difference between the specific humidity of the air at the ocean surface (considered saturated) and that of the air in the atmospheric boundary layer; this is strongly related to the air-sea temperature difference.

\section{b. Analysis of latent heating variability}

The following discussion explores factors contributing to the variance of $Q_{l h}$ and the spectral distribution of its variance and shows that the variance in the latent heat flux (the dominant surface flux component) is primarily due to variations in wind speed.

The latent heat flux term can be written as

$$
\begin{aligned}
Q_{l h}= & L \rho C_{e}\left(\{w\}+w^{\prime \prime}\right) \\
& \times\left(\left\{q_{a i r}\right\}+q_{a i r}^{\prime \prime}-\left\{q_{\text {sat }}\right\}-q_{\text {sat }}^{\prime \prime}\right),
\end{aligned}
$$

where $L$ is the latent heat of vaporization of water, $\rho$ is the density of air, $C_{e}$ is the bulk exchange coefficient (which is a function of wind speed and atmospheric stability), $w$ is the wind speed, $q_{a i r}$ is the observed specific humidity (mass water vapor/mass dry air), and $q_{\text {sat }}$ is the saturation specific humidity at the temperature of the ocean surface. The curly brackets (e.g., $\{w\}$ ) denote the climatological annual cycle and the double prime (e.g., $w^{\prime \prime}$ ) denotes the daily averaged anomaly about the climatological mean annual cycle or the anomaly; thus, $w=\{w\}+w^{\prime \prime}$.

The contribution to the variance of $Q_{l h}^{\prime \prime}$ due to the covariance of $w^{\prime \prime}$ and $\left(q_{a i r}^{\prime \prime}-q_{s a t}^{\prime \prime}\right)$ is $4 \%$ in summer, $9 \%$ in winter, and about 7\% throughout the year (see Table 2 ). Since the covariance of $w^{\prime \prime}$ and $q_{a i r}^{\prime \prime}-q_{s a t}^{\prime \prime}$ does not contribute significantly to the variance in $Q_{l h}^{\prime \prime}$ (see also Esbensen and Reynolds 1981), the following linearization is a good approximation to $Q_{l h}^{\prime \prime}$ :

$$
\begin{aligned}
Q^{\prime \prime}{ }_{l h} \approx L\{\rho\}\left\{C_{e}\right\}\left[w^{\prime \prime}\right. & \left(\left\{q_{a i r}-q_{s a t}\right\}\right) \\
& \left.+\{w\}\left(q^{\prime \prime}{ }_{a i r}-q_{\text {sat }}^{\prime \prime}\right)\right] .
\end{aligned}
$$

Using Eq. 2, the relative contributions of $w^{\prime \prime}, q_{\text {air }}^{\prime \prime}$, and $q_{s a t}^{\prime \prime}$ to $Q_{l h}^{\prime \prime}$ are determined and are summarized in Table 2 . From this table, it is clear that wind speed contributes the most to daily latent heat anomalies, followed in importance by $\left(q_{a i r}^{\prime \prime}-q_{s a t}^{\prime \prime}\right)$. Note that although the exchange coefficient, $C_{e}$, has an annual cycle and anomalies, variability in $C_{e}$ contributes little to the variance of $Q_{l h}^{\prime \prime}$ and will not be discussed here. From Table 2 it 
TABLE 1. Correlation coefficients between monthly anomalies in the surface energy fluxes, and the variances and means of the monthly anomalies for all of the months, for summer only (JJASO) and for winter only (DJFMA). The components of the net surface energy flux $\left(Q_{n e t}\right)$ are solar $\left(Q_{s w}\right)$, latent $\left(Q_{l h}\right)$, sensible $\left(Q_{s h}\right)$, and net longwave $\left(Q_{l w}\right)$. All fluxes are taken to be positive downward. Correlation coefficients that are significantly greater than zero at the $95 \%$ level are in bold type. Data for one-season only or for all of the months have 55 or 132 degrees of freedom, respectively. With the Student's $t$ test, therefore, it is established that a correlation coefficient of magnitude greater than 0.20 or 0.23 is significantly greater than zero at the $95 \%$ level, assuming 130 or 55 degrees of freedom, respectively. The reader is referred to section $4 \mathrm{e}$ for a discussion of the ocean advective heat flux, $Q_{a d v}$.

\begin{tabular}{|c|c|c|c|c|c|c|c|c|}
\hline $\begin{array}{c}\text { Correlation } \\
\text { coefficient }\end{array}$ & $\begin{array}{c}Q_{s w} \\
\text { (JJASO) } \\
\text { (DJFMA) }\end{array}$ & $\begin{array}{c}Q_{l w} \\
\text { (JJASO) } \\
\text { (DJFMA) }\end{array}$ & $\begin{array}{c}Q_{l h} \\
\text { (JJASO) } \\
\text { (DJFMA) }\end{array}$ & $\begin{array}{c}Q_{s h} \\
\text { (JJASO) } \\
\text { (DJFMA) }\end{array}$ & $\begin{array}{c}Q_{a d v} \\
\text { (JJASO) } \\
\text { (DJFMA) }\end{array}$ & $\begin{array}{c}Q_{s w}+Q_{l w} \\
+Q_{l h}+Q_{s h} \\
\text { (JJASO) } \\
\text { (DJFMA) }\end{array}$ & $\begin{array}{c}\text { Variance } \\
\left(\mathrm{W} \mathrm{m}^{-2}\right)^{2}\end{array}$ & $\begin{array}{c}\text { Mean } \\
\left(\mathrm{W} \mathrm{m}^{-2}\right)\end{array}$ \\
\hline \multicolumn{9}{|l|}{$Q_{s w}$} \\
\hline (All months) & 1 & & & & & & 74 & 160 \\
\hline (JJASO) & 1 & & & & & & 129 & 196 \\
\hline (DJFMA) & 1 & & & & & & 40 & 125 \\
\hline \multicolumn{9}{|l|}{$Q_{l w}$} \\
\hline (All months) & -0.59 & 1 & & & & & 12 & -43 \\
\hline (JJASO) & -0.79 & 1 & & & & & 8 & -43 \\
\hline (DJFMA) & -0.56 & 1 & & & & & 17 & -43 \\
\hline \multicolumn{9}{|l|}{$Q_{l h}$} \\
\hline (All months) & 0.22 & 0.38 & 1 & & & & 482 & -105 \\
\hline (JJASO) & 0.32 & 0.10 & 1 & & & & 307 & -99 \\
\hline (DJFMA) & 0.30 & 0.43 & 1 & & & & 617 & -109 \\
\hline \multicolumn{9}{|l|}{$Q_{s h}$} \\
\hline (All months) & 0.15 & 0.56 & 0.86 & 1 & & & 21 & -10 \\
\hline (JJASO) & 0.26 & 0.22 & 0.84 & 1 & & & 9 & -8 \\
\hline (DJFMA) & 0.13 & 0.68 & 0.85 & 1 & & & 32 & -12 \\
\hline \multicolumn{9}{|l|}{$Q_{a d v}$} \\
\hline (All months) & -0.23 & 0.31 & -0.12 & -0.00 & 1 & & 221 & 13 \\
\hline (JJASO) & -0.29 & 0.03 & -0.71 & -0.65 & 1 & & 34 & 11 \\
\hline (DJFMA) & -0.45 & 0.42 & -0.09 & 0.02 & 1 & & 457 & 16 \\
\hline \multicolumn{9}{|c|}{$Q_{n e t}=\left(Q_{s w}+Q_{l w}+Q_{l h}+Q_{s h}\right)$} \\
\hline (All months) & 0.40 & 0.31 & 0.97 & 0.89 & -0.12 & 1 & 899 & 1.1 \\
\hline (JJASO) & 0.60 & -0.14 & 0.94 & 0.84 & $-\mathbf{0 . 7 0}$ & 1 & 650 & 47 \\
\hline (DJFMA) & 0.35 & 0.45 & 0.99 & 0.90 & -0.09 & 1 & 1130 & -39 \\
\hline
\end{tabular}

is also clear that the variability in $q_{a i r}^{\prime \prime}$ contributes more to the overall variance of $Q_{l h}^{\prime \prime}$ than does $q_{s a t}^{\prime \prime}{ }^{4}$

The power spectra of some of the components of fiveday averages of $Q_{l h}^{\prime \prime}$ are shown in Fig. 2. The fraction of variance of latent heat flux anomaly that is independent of anomalies in wind speed $\left[L C_{e}\{w\}\left(q_{a i r}^{\prime \prime}-q_{s a t}^{\prime \prime}\right)\right]$ is less than one-half of the variance of the full latent heat flux anomaly at most frequencies and decreases with increasing frequency. The power spectrum of the $Q_{l h}^{\prime \prime}$ component independent of $q_{s a t}^{\prime \prime}$,

$$
L C_{e} w^{\prime \prime}\left(\left\{q_{a i r}-q_{s a t}\right\}+L C_{e}\{w\} q_{a i r}^{\prime \prime},\right.
$$

(not shown) is nearly identical to the power spectrum of the total $Q_{l h}^{\prime \prime}$. Since $q_{\text {sat }}$ depends only on SST, SST is not significant in determining the variance of $Q_{l h}$ at seasonal and shorter timescales. Wind speed, however, is central to the determination of $Q_{l h}$ at all frequencies.

The statistical significance of peaks in a power spec-

\footnotetext{
${ }^{4}$ Because SST" and $T_{a i r}^{\prime \prime}$ are closely linked, $q_{a i r}^{\prime \prime}-q_{s a t}^{\prime \prime}$ has less variance than $q_{a i r}^{\prime \prime}$ alone. This accounts for the values greater than $100 \%$ in Table 2.
}

trum may be assessed by comparing the observed variance in a particular frequency band to a red-noise spectrum (Gilman et al. 1963). The power spectrum of $Q_{l h}^{\prime \prime}$ in Fig. 2 shows enhanced variance at periods around 80 days; this peak in variance is statistically significant at the $80 \%$ level using a posteriori statistics. However, the latent heating anomalies during the years 1955-60 (not shown) also have enhanced variance at about 80-day periods at the $80 \%$ significance level, thus the peak may

TABLE 2. Contributions of wind speed and $q_{\text {sat }}-q_{a i r}$ to daily anomalies in latent heating. Table entries are in percent, and they indicate the variance in the heat flux calculated using the expressions in column 1 compared to the variance in latent heat flux.

\begin{tabular}{|c|c|c|c|}
\hline $\begin{array}{l}\text { Variance in the term below } \\
\text { compared to the variance in } \\
\text { the latent heat flux anomaly } \\
\text { (expressed as a percentage) }\end{array}$ & $\begin{array}{c}\text { All } \\
\text { months }\end{array}$ & $\begin{array}{c}\text { Summer } \\
\text { months } \\
\text { (JJA) } \\
\text { only }\end{array}$ & $\begin{array}{l}\text { Winter } \\
\text { months } \\
\text { (DJF) } \\
\text { only }\end{array}$ \\
\hline$L \rho C_{e} w^{\prime \prime}\left\{q_{s a t}-q_{a i}\right.$ & $67 \%$ & $89 \%$ & $58 \%$ \\
\hline$L \rho C_{e}\{w\}\left(q_{\text {sat }}-q_{\text {air }}\right)^{\prime \prime}$ & $35 \%$ & $22 \%$ & $49 \%$ \\
\hline$L \rho C_{e} w^{\prime \prime}\left\{q_{s a t}-q_{a i r}\right\}+L \rho C_{e}\{w\}\left(-q_{a i r}\right)^{\prime \prime}$ & $102 \%$ & $116 \%$ & $97 \%$ \\
\hline$L \rho C_{e} w^{\prime \prime}\left\{q_{s a t}-q_{a i r}\right\}+\operatorname{L\rho } C_{e}\{w\}\left(q_{\text {sat }}\right)^{\prime \prime}$ & $71 \%$ & $94 \%$ & $66 \%$ \\
\hline$L \rho C_{e} w^{\prime \prime}\left(q_{s a t}-q_{a i r}\right)^{\prime \prime}$ & $7 \%$ & $4 \%$ & $9 \%$ \\
\hline
\end{tabular}




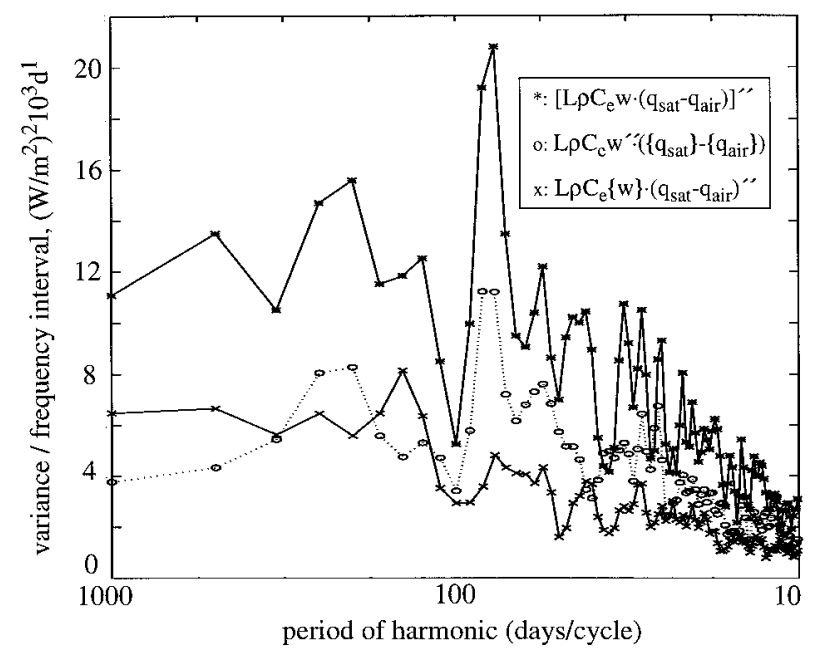

FIG. 2. Power spectra of daily latent heat flux anomalies. The wind speed variability is responsible for most of the variability in latent heating. The sum of the curve with circles and the curve with "x's" is approximately the power spectrum of the complete latent heating anomaly (stars).

be considered significant at the $95 \%$ confidence level using a priori statistics.

Figure 3 shows the spectrum of wind speed anomalies $\left(w^{\prime \prime}\right)$. This spectrum displays enhanced variance at $\sim 80$ day periods, supporting the finding that the enhanced variance in $Q_{l h}$ at that frequency is due to variability in wind speed. By comparing the OWS $\mathrm{N}$ data to white noise and using a posteriori statistics (Julian 1971), the wind speed variance at $\sim 80$-day periods is the only statistically significant band above the $80 \%$ confidence level. The power spectrum of the wind speed during the years 1955-60 (not shown) also has enhanced variance at the $\sim 80$-day period, thus the peak may be considered significant at the $95 \%$ confidence level using a priori statistics.

\section{c. Analysis of shortwave radiation variability}

The monthly anomaly of the shortwave energy flux, $Q_{s w}^{\prime}$, has the second largest variance of the four surface energy flux anomalies (see Table 1). Anomalies in $Q_{s w}$ are largely due to changes in cloud amount; the correlation coefficient between monthly cloud anomalies and $Q_{s w}^{\prime}$ is -0.93 annually, -0.97 in summer, and -0.93 in winter (see Table 3). A linear regression between anomalies in cloud amount and $Q_{s w}^{\prime}$ indicates a one-tenth change in cloudiness corresponds to a $16 \mathrm{~W} \mathrm{~m}^{-2}$ change in $Q_{s w}^{\prime}$. This is in good agreement with the relationship between cloud amount and $Q_{s w}^{\prime}$ found using a radiative transfer model, which yields a $20 \mathrm{~W} \mathrm{~m}^{-2}$ change in downward solar radiation at the surface for a one-tenth change in cloudiness (Ronca 1995).

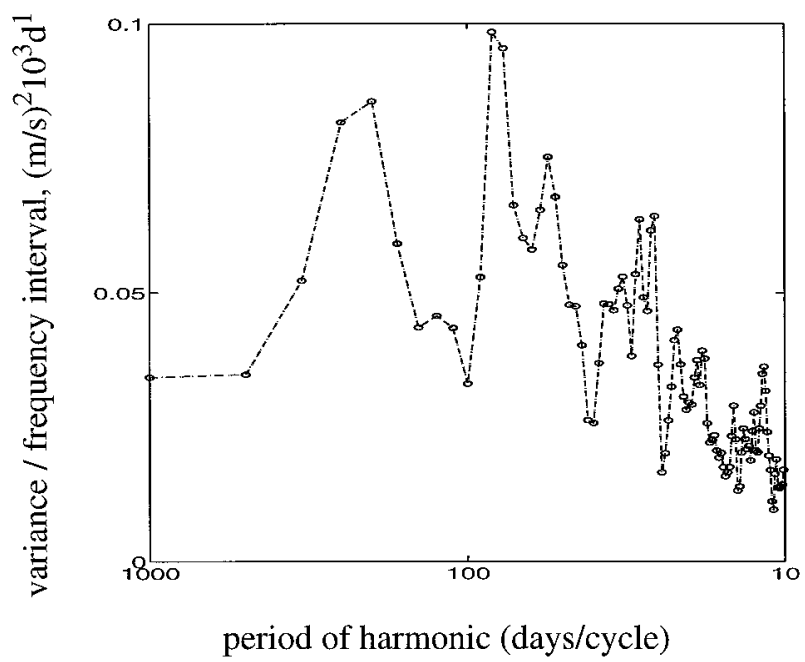

FIG. 3. Power spectra of observed wind speed at OWS N.

\section{d. Covariance analysis between surface energy fluxes and SST and SST tendency}

The covariance of a particular surface energy flux anomaly, $Q_{i}^{\prime}$, with $\mathrm{SST}^{\prime}$ is denoted $\left\langle Q_{i}^{\prime}, \mathrm{SST}^{\prime}\right\rangle$. The total combined covariance of all of the surface energy flux anomalies with $\mathrm{SST}^{\prime}$ or with $\mathrm{SST}^{\prime}$ tendency, $\partial \mathrm{SST}^{\prime} / \partial t$, may be expressed as

$$
\sqrt{\sum_{i=1}^{i=4}\left(\left\langle Q_{i}^{\prime}, \mathrm{SST}^{\prime}\right\rangle\right)^{2}}
$$

and

$$
\sqrt{\sum_{i=1}^{i=4}\left(\left\langle Q_{i}^{\prime}, \frac{\partial}{\partial t} \mathrm{SST}^{\prime}\right\rangle\right)^{2}}, \quad \text { respectively. }
$$

Figure 4 shows the covariance of each of the surface energy flux anomalies with $\partial \mathrm{SST}^{\prime} / \partial t$ or $\mathrm{SST}^{\prime}$ normalized by the appropriate combined covariance [as defined in Eq. (3)]. For example, the normalized covariance of $Q_{l h}^{\prime}$ with $\partial \mathrm{SST}^{\prime} / \partial t$ is

$$
\frac{\left\langle Q_{l h}^{\prime}, \frac{\partial}{\partial t} \mathrm{SST}^{\prime}\right\rangle}{\left[\sum_{i=1}^{i=4}\left(\left\langle Q_{i}^{\prime}, \frac{\partial}{\partial t} \mathrm{SST}^{\prime}\right\rangle\right)^{2}\right]^{1 / 2}}=0.97 .
$$

Thus, the covariance of the latent heating anomaly accounts for almost all of the combined covariance of the surface energy fluxes with $\partial \mathrm{SST}^{\prime} / \partial t$. The covariance of $\mathrm{SST}^{\prime}$ with the four surface energy fluxes is dominated by $Q_{s w}^{\prime}$, which covaries positively with $\mathrm{SST}^{\prime}$, and by $Q_{l h}^{\prime}$, which covaries negatively with $\mathrm{SST}^{\prime}$.

If the surface energy flux anomalies are projected onto the values shown in Fig. 4, the result is a time series that represents the covariance of the combined surface energy fluxes with $\partial \mathrm{SST}^{\prime} / \partial t$ or $\mathrm{SST}^{\prime}$. This time series 
TABLE 3. Correlation coefficients between monthly anomalies in the surface energy fluxes and observed variables, and the variances of the observed variables. Correlation coefficients that are significantly greater than zero at the $95 \%$ level are in bold type. SST' and $\partial \mathrm{SST}^{\prime} /$ $\partial t$ have one-lag autocorrelations of 0.61 and 0.38 , respectively; based on Leith's (Leith 1973) formula, the one-season SST ${ }^{\prime}$ and $\partial \mathrm{SST}^{\prime} / \partial t$ have 14 and 27 degrees of freedom, respectively. Therefore, for summer or winter only, correlation coefficients between any time series and $\mathrm{SST}^{\prime}$ or $\partial \mathrm{SST}^{\prime} / \partial t$ that have magnitude greater than 0.45 and 0.32 , respectively, are significantly differently above zero at the $95 \%$ level.

\begin{tabular}{|c|c|c|c|c|c|c|c|}
\hline Anomalies & $\begin{array}{c}Q_{s w} \\
\text { (JJASO) } \\
\text { (DJFMA) }\end{array}$ & $\begin{array}{c}Q_{l w} \\
\text { (JJASO) } \\
\text { (DJFMA) }\end{array}$ & $\begin{array}{c}Q_{l h} \\
\text { (JJASO) } \\
\text { (DJFMA) }\end{array}$ & $\begin{array}{c}Q_{s h} \\
\text { (JJASO) } \\
\text { (DJFMA) }\end{array}$ & $\begin{array}{c}Q_{\text {advect }} \\
\text { (JJASO) } \\
\text { (DJFMA) }\end{array}$ & $\begin{array}{c}Q_{s w}+Q_{l w} \\
+Q_{l h}+Q_{s h} \\
\text { (JJASO) } \\
\text { (DJFMA) }\end{array}$ & $\begin{array}{l}\text { Variance } \\
\text { in field }\end{array}$ \\
\hline \multicolumn{8}{|l|}{ Wind speed } \\
\hline $\begin{array}{l}\text { (All months) } \\
\text { (JJASO) } \\
\text { (DJFMA) }\end{array}$ & $\begin{array}{l}-0.41 \\
-0.51 \\
-0.52\end{array}$ & $\begin{array}{l}0.26 \\
0.27 \\
0.34\end{array}$ & $\begin{array}{l}-0.64 \\
-0.81 \\
-0.55\end{array}$ & $\begin{array}{l}-0.36 \\
-0.63 \\
-0.22\end{array}$ & $\begin{array}{l}0.35 \\
0.64 \\
0.37\end{array}$ & $\begin{array}{l}-0.62 \\
-0.83 \\
-0.50\end{array}$ & $\begin{array}{l}0.86\left(\mathrm{~m} \mathrm{~s}^{-1}\right)^{2} \\
0.69 \\
1.1\end{array}$ \\
\hline \multicolumn{8}{|l|}{$\partial\left(\mathrm{SST}^{\prime}\right) / \partial t$} \\
\hline $\begin{array}{l}\text { (All months) } \\
\text { (JJASO) } \\
\text { (DJFMA) }\end{array}$ & $\begin{array}{l}\mathbf{0 . 2 4} \\
\mathbf{0 . 3 4} \\
0.07\end{array}$ & $\begin{array}{l}0.24 \\
0.02 \\
\mathbf{0 . 3 2}\end{array}$ & $\begin{array}{l}0.59 \\
0.65 \\
0.53\end{array}$ & $\begin{array}{l}0.48 \\
0.56 \\
0.41\end{array}$ & $\begin{array}{r}0.12 \\
-\mathbf{0 . 3 7} \\
\mathbf{0 . 3 3}\end{array}$ & $\begin{array}{l}0.60 \\
0.67 \\
0.51\end{array}$ & $\begin{array}{l}0.1\left({ }^{\circ} \mathrm{C} \mathrm{mo}^{-1}\right)^{2} \\
0.2 \\
0.1\end{array}$ \\
\hline \multicolumn{8}{|l|}{ SST } \\
\hline $\begin{array}{l}\text { (All months) } \\
\text { (JJASO) } \\
\text { (DJFMA) }\end{array}$ & $\begin{array}{r}\mathbf{0 . 3 1} \\
\mathbf{0 . 4 9} \\
-0.10\end{array}$ & $\begin{array}{r}-0.10 \\
-0.39 \\
0.21\end{array}$ & $\begin{array}{l}-0.08 \\
-0.08 \\
-0.03\end{array}$ & $\begin{array}{l}-0.004 \\
-0.06 \\
0.14\end{array}$ & $\begin{array}{l}-0.03 \\
-0.05 \\
-0.08\end{array}$ & $\begin{array}{l}0.01 \\
0.11 \\
0.01\end{array}$ & $\begin{array}{l}0.3\left({ }^{\circ} \mathrm{C}\right)^{2} \\
0.5 \\
0.2\end{array}$ \\
\hline $\begin{array}{l}\text { Total cloud fract } \\
\text { (All months) } \\
\text { (JJASO) } \\
\text { (DJFMA) }\end{array}$ & $\begin{array}{l}-0.93 \\
-0.97 \\
-0.93\end{array}$ & $\begin{array}{l}0.61 \\
0.79 \\
0.54\end{array}$ & $\begin{array}{r}0.26 \\
-0.36 \\
-0.31\end{array}$ & $\begin{array}{l}-0.20 \\
-\mathbf{0 . 3 2} \\
-0.18\end{array}$ & $\begin{array}{l}0.32 \\
0.38 \\
0.51\end{array}$ & $\begin{array}{l}-0.42 \\
-0.63 \\
-0.37\end{array}$ & $\begin{array}{l}35(\% \text { sky cover })^{2} \\
48 \\
29\end{array}$ \\
\hline
\end{tabular}

is called the principal component and is equivalent to the principal component generated in an SVD analysis of the surface energy flux anomalies with a $\partial \mathrm{SST}^{\prime} / \partial t$ or $\mathrm{SST}^{\prime}$. The principal components generated by the covariance analysis of the surface energy flux anomalies with $\partial \mathrm{SST}^{\prime} / \partial t$ and $\mathrm{SST}^{\prime}$ are abbreviated as $\mathrm{PC}\left(\partial \mathrm{SST}^{\prime} /\right.$ $\partial t)$ or $\mathrm{PC}\left(\mathrm{SST}^{\prime}\right)$ respectively.

The correlation coefficients between the $\mathrm{PC}\left(\partial \mathrm{SST}^{\prime} /\right.$ $\partial t)$ and $\partial \mathrm{SST}^{\prime} / \partial t$ and between $\mathrm{PC}\left(\mathrm{SST}^{\prime}\right)$ and $\mathrm{SST}^{\prime}$ are a test for the significance of the covariance. The correlation coefficient between $\mathrm{PC}\left(\partial \mathrm{SST}^{\prime} / \partial t\right)$ and $\partial \mathrm{SST}^{\prime} / \partial t$ is 0.6 , significantly above zero at the $99 \%$ level; the correlation coefficient between $\mathrm{PC}\left(\mathrm{SST}^{\prime}\right)$ and $\mathrm{SST}^{\prime}$ is 0.24 and is not significant at the $95 \%$ level. Thus, when

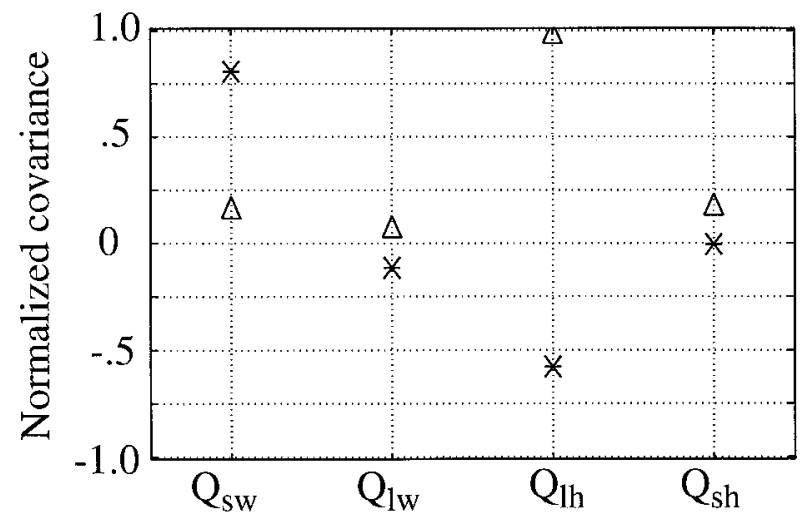

FIG. 4. Normalized covariance of surface (monthly mean) energy flux anomalies with $\partial \mathrm{SST}^{\prime} / \partial t$ (triangles) and with $\mathrm{SST}^{\prime}$ (stars). All months included. all of the months are considered together, the covariance of the monthly averaged surface energy flux anomalies with $\partial \mathrm{SST}^{\prime} / \partial t$ is significant, and the covariance of the surface energy flux anomalies with $S S T^{\prime}$ is not.

Another useful quantity in interpreting the covariance analysis is the percent of the total summed variances of the surface energy flux anomalies explained by the principal component. The variance of $\mathrm{PC}\left(\partial \mathrm{SST}^{\prime} / \partial t\right)$ is $85 \%$ of the summed variances of the surface energy fluxes:

$$
\frac{\left\langle\mathrm{PC}\left(\frac{\partial}{\partial t} \mathrm{SST}^{\prime}\right), \mathrm{PC}\left(\frac{\partial}{\partial t} \mathrm{SST}^{\prime}\right)\right\rangle}{\sum_{i=i}^{i=4}\left\langle Q_{i}, Q_{i}\right\rangle}=0.85 .
$$

Thus, the surface energy flux anomalies covary significantly with $\partial \mathrm{SST}^{\prime} / \partial t$, and their covariance with $\partial \mathrm{SST}^{\prime} /$ $\partial t$ explains fully $85 \%$ of the summed variance in all of the components of the surface heat flux.

\section{e. Comparison of the dominant surface energy flux modes in summer and winter}

The monthly anomalies of the surface energy flux anomalies, $\mathrm{SST}^{\prime}$ and $\partial \mathrm{SST}^{\prime} / \partial t$, are divided into the "winter" season, DJFMA, and the "summer" season, JJASO, so that processes dominant in each season may be distinguished. The results of the covariance analyses of the surface energy flux anomalies with $\mathrm{SST}^{\prime}$ and with $\partial \mathrm{SST}^{\prime} / \partial t$ for each season are shown in Figs. 5 and 6, respectively. 


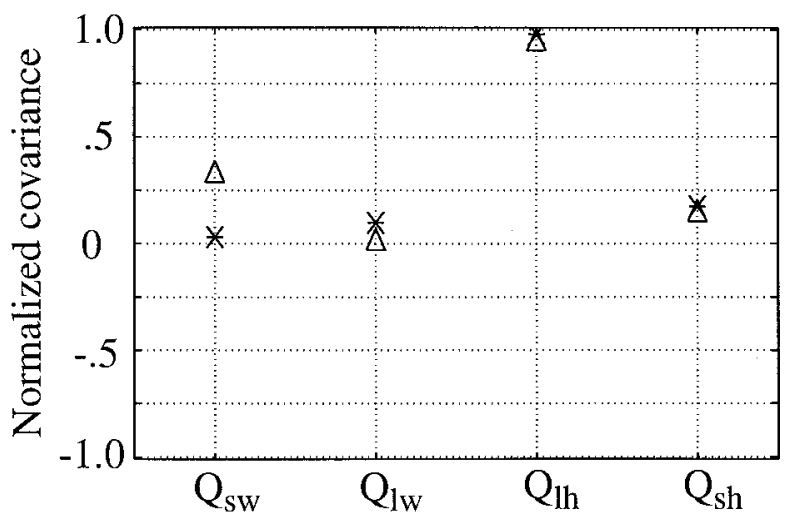

FIG. 5. Normalized covariance of surface energy flux (monthly mean) anomalies with $\partial \mathrm{SST}^{\prime} / \partial t$ in the summer (triangles, JJASO) and in the winter (stars, DJFMA). The correlation coefficient between $\mathrm{PC}\left(\partial \mathrm{SST}^{\prime} / \partial t\right)$ and $\partial \mathrm{SST}^{\prime} / \partial t$ is 0.7 in the summer and 0.5 in the winter. The variance of $\mathrm{PC}\left(\partial \mathrm{SST}^{\prime} / \partial t\right)$ is $74 \%$ (summer) and $91 \%$ (winter) of the sum of the variance in each of the surface energy flux components.

The correlation coefficients between $\mathrm{PC}\left(\partial \mathrm{SST}^{\prime} / \partial t\right)$ and $\partial \mathrm{SST}^{\prime} / \partial t$ for the summer and winter are 0.7 and 0.5 , respectively, both significantly above zero at the 99\% level. In both seasons, the covariance of $Q_{l h}^{\prime}$ with $\partial \mathrm{SST}^{\prime} / \partial t$ dominates the total combined covariance [defined in Eq. (3)]; the shortwave flux is second in importance in determining the covariance of the surface fluxes with $\partial \mathrm{SST}^{\prime} / \partial t$ in summer.

The variance of $\mathrm{PC}\left(\partial \mathrm{SST}^{\prime} / \partial t\right)$ is $74 \%$ and $91 \%$ of the summed variances of the surface energy flux anomalies in summer and winter, respectively. Thus, most of the surface energy flux variability covaries with $\partial \mathrm{SST}^{\prime} /$ $\partial t$, and more so in the winter than in the summer.

The correlation coefficients between $\mathrm{PC}\left(\mathrm{SST}^{\prime}\right)$ and $\mathrm{SST}^{\prime}$ for the summer and winter are 0.5 (95\% significant) and 0.1 (not significant), respectively. Thus, the

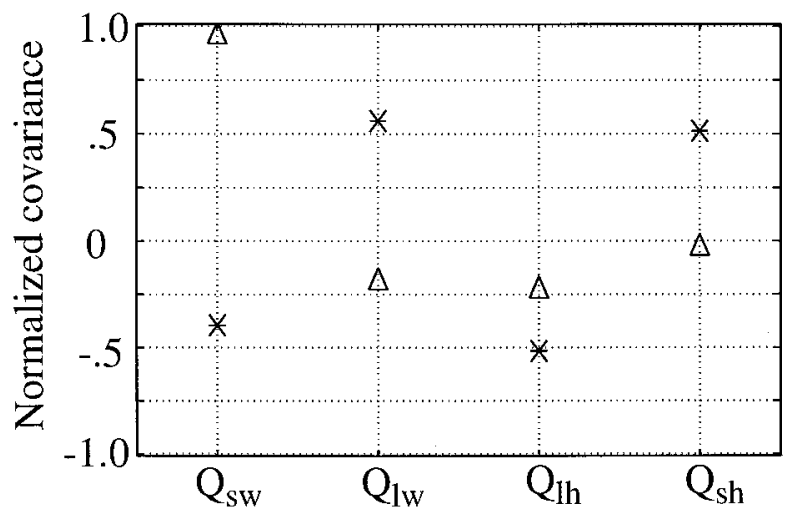

FIG. 6. Normalized covariance of surface energy flux (monthly mean) anomalies with SST' in the summer (triangles, JJASO) and in the winter (stars, DJFMA). The correlation coefficient between $\mathrm{PC}\left(\mathrm{SST}^{\prime}\right)$ and $\mathrm{SST}^{\prime}$ is 0.5 in the summer and 0.1 in the winter. The variance of $\mathrm{PC}\left(\mathrm{SST}^{\prime}\right)$ is $26 \%$ (summer) and $18 \%$ (winter) of the summed variances of the surface energy fluxes. In the summer, $\mathrm{PC}\left(\mathrm{SST}^{\prime}\right)$ is nearly orthogonal to $\mathrm{PC}\left(\partial \mathrm{SST}^{\prime} / \partial t\right)$ : the correlation coefficient between the two is 0.12 . surface energy flux anomalies covary significantly (at the $95 \%$ level) with $\mathrm{SST}^{\prime}$ in the summer only; specifically, $26 \%$ of the variance in all of the summertime surface energy flux anomalies covaries with $\mathrm{SST}^{\prime}$. The covariance of the surface energy flux anomalies with $\mathrm{SST}^{\prime}$ is dominated by $Q_{s w}^{\prime}$, which covaries positively with $\mathrm{SST}^{\prime}$. The other fluxes account for less than $25 \%$ of the total combined covariance, and they all covary negatively with $\mathrm{SST}^{\prime}$.

The correlation coefficient between the summertime $\mathrm{PC}\left(\partial \mathrm{SST}^{\prime} / \partial t\right)$ and $\mathrm{PC}\left(\mathrm{SST}^{\prime}\right)$ is 0.12 ; thus, the two principal components are nearly orthogonal. Since $\mathrm{PC}\left(\partial \mathrm{SST}^{\prime} / \partial t\right)$ and $\mathrm{PC}\left(\mathrm{SST}^{\prime}\right)$ are nearly orthogonal and describe, respectively, $74 \%$ and $26 \%$ of the variance of the summertime surface energy flux anomalies, they must, together, almost completely describe all of the variance in the components of the surface energy flux anomalies. ${ }^{5}$ It follows that the summertime surface energy flux anomalies have two degrees of freedom: the combination that covaries with $\partial \mathrm{SST}^{\prime} / \partial t$ and the combination that covaries with $\mathrm{SST}^{\prime}$.

\section{f. Relationship between anomalies in SST, surface shortwave flux, and net surface heat flux during summertime}

Thus far, this analysis has been confined to the individual surface flux anomalies and how they are related to each other. The following is a discussion of the variance of the net surface energy flux anomaly, $Q_{n e t}^{\prime}(=$ $\left.Q_{s w}^{\prime}+Q_{l w}^{\prime}+Q_{l h}^{\prime}+Q_{s h}^{\prime}\right)$.

The component of the summertime net surface energy flux that covaries with $\mathrm{SST}^{\prime}$ (see the triangles in Fig. 6), $Q_{\mathrm{SST}}^{\prime}$, is

$$
\begin{aligned}
Q_{\mathrm{SST}}^{\prime}= & \{(0.95)+(-0.19)+(-0.23) \\
& +(-0.03)\} \mathrm{PC}\left(\mathrm{SST}^{\prime}\right) .
\end{aligned}
$$

In the summer, the variance of the net surface energy flux and the variance of the component of the net surface energy flux that covaries with $\partial \mathrm{SST}^{\prime} / \partial t$ are both $\sim 650$ $\mathrm{W}^{2} \mathrm{~m}^{-4}$. The variance of $Q_{\mathrm{SST}}^{\prime}$ in Eq.(4) is $\sim 28 \mathrm{~W}^{2} \mathrm{~m}^{-4}$. Thus, the component of the net surface energy flux that covaries with $\mathrm{SST}^{\prime}$ is only $\sim 4 \%$ of the net flux, although the covariance of $\mathrm{SST}^{\prime}$ with the individual surface energy fluxes describes about $26 \%$ of the summed variances of the surface energy flux anomalies. This follows because the latent, sensible, and longwave anomalies all

\footnotetext{
${ }^{5}$ This is confirmed by an empirical orthogonal function (EOF) analysis of the summertime surface energy flux anomalies. The first EOF has a structure that is almost identical to the combination of fluxes shown in Fig. 5. The second EOF is almost identical to the combination of fluxes shown in Fig. 6. Furthermore, the first two EOF combinations describe nearly $100 \%$ of the variance of the surface energy flux anomalies.
} 
negatively covary with $\mathrm{SST}^{\prime}$, and the shortwave anomaly covaries positively with $\mathrm{SST}^{\prime}$. Thus, there is significant cancellation between the $Q_{s w}^{\prime}$ and the other fluxes, and the net flux that covaries with $\mathrm{SST}^{\prime}$ does not significantly affect the energy balance of the mixed layer of the ocean.

What, then, determines the relationship between the summertime surface energy flux anomalies and $\mathrm{SST}^{\prime}$ ? Is $\mathrm{SST}^{\prime}$ responding rapidly to the surface energy flux anomalies (mainly $Q_{s w}^{\prime}$ )? Or is the lower atmosphere (mainly $Q_{s w}^{\prime}$ ) forced by $\mathrm{SST}^{\prime}$ ? Because the net forcing that covaries with $\mathrm{SST}^{\prime}$ is relatively small, it is unlikely that this variability in the surface energy flux could cause significant changes in SST. On the other hand, the hypothesis that variability in SST causes these surface fluxes to change is consistent with the observed variances and correlations. Thus, we propose the covariance pattern of surface energy flux anomalies with $\mathrm{SST}^{\prime}$ is $d u e$ to the dependence of the surface energy flux anomalies on $\mathrm{SST}^{\prime}$, including solar heat flux, and represents some processes by which the ocean forces the atmosphere. The physical explanation of how this forcing may occur is in section $3 \mathrm{~h}$.

\section{g. Lead-lag analysis of surface fluxes}

The covariance of the surface energy fluxes with $\partial \mathrm{SST}^{\prime} / \partial t$ shows that atmospheric variability forces variability in $\mathrm{SST}^{\prime}$ primarily by $Q_{l h}^{\prime}$. Furthermore, the covariance of the summertime anomalies in the surface energy fluxes with $\mathrm{SST}^{\prime}$ indicates that some variability in the fluxes is a response to summertime $\mathrm{SST}^{\prime}$.

If the surface energy fluxes that force SST variability were independent of the surface energy fluxes that respond to variability in $\mathrm{SST}, \mathrm{PC}\left(\partial \mathrm{SST}^{\prime} / \partial t\right)$ and $\mathrm{PC}\left(\mathrm{SST}^{\prime}\right)$ would not be related. The lead-lag correlation analysis between the summertime $\mathrm{PC}\left(\partial \mathrm{SST}^{\prime} / \partial t\right)$ and $\mathrm{PC}\left(\mathrm{SST}^{\prime}\right)$ is shown in Fig. 7. There is a significant (at the 95\% confidence level) correlation coefficient for $\mathrm{PC}\left(\partial \mathrm{SST}^{\prime} /\right.$ $\partial t$ ) leading $\mathrm{PC}\left(\mathrm{SST}^{\prime}\right)$ by one month. Thus, the two dominant patterns of variability of the summertime surface energy flux anomalies are not independent. The leadlag correlation analysis indicates that the surface energy flux anomalies that force $\mathrm{SST}^{\prime}$ variability (dominated by latent heating) are related to the surface energy flux anomalies that are forced by SST' (dominated by solar heating) about one month later.

The lead-lag analysis between the summertime $Q_{l h}^{\prime}$ and $Q_{s w}^{\prime}$ (also in Fig. 7) shows that they are significantly correlated when $Q_{l h}^{\prime}$ leads by one month, suggesting that an increase in $Q_{l h}^{\prime}$ is related to an increase in $Q_{s w}^{\prime}$ one month later. Unlike $\mathrm{PC}\left(\partial \mathrm{SST}^{\prime} / \partial t\right)$ and $\mathrm{PC}\left(\mathrm{SST}^{\prime}\right)$, however, $Q_{l h}^{\prime}$ and $Q_{s w}^{\prime}$ are also significantly correlated at zero lag, possibly because both $Q_{l h}^{\prime}$ and $Q_{s w}^{\prime}$ are significantly correlated with wind speed in the summertime (see Table 3).

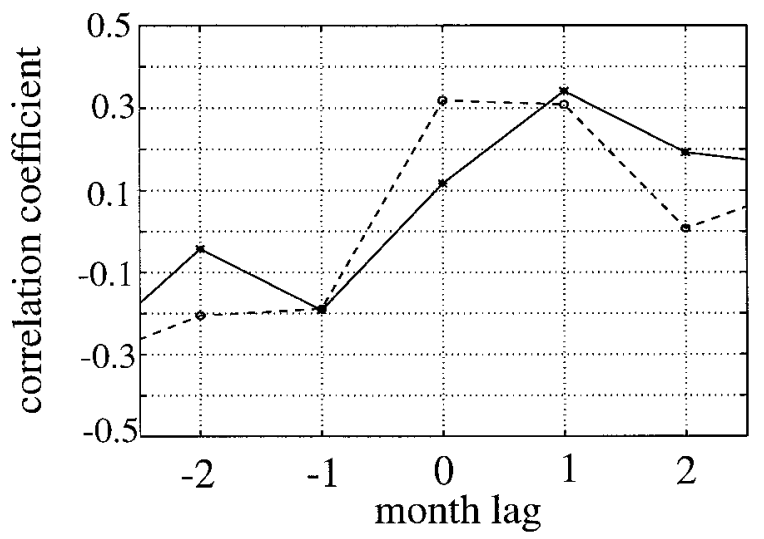

FIG. 7. Lead-lag analysis for the summer months (JJASO) between $Q_{s w}^{\prime}$ and $Q_{l h}^{\prime}$ (dashed line) and between $\operatorname{PC}\left(\partial \mathrm{SST}^{\prime} / \partial t\right)$ and $\mathrm{PC}\left(\mathrm{SST}^{\prime}\right)$ (solid line). Terms $Q_{l h}^{\prime}$ and $\mathrm{PC}\left(\partial \mathrm{SST}^{\prime} / \partial t\right)$ lead $Q_{s w}^{\prime}$ and $\mathrm{PC}\left(\mathrm{SST}^{\prime}\right)$, respectively, for positive lag. A correlation coefficient of magnitude greater than 0.23 is significantly different from zero at the $95 \%$ level. Zero lag is the correlation coefficient calculated for all of the summer months (JJASO), one lag (or lead) is the correlation coefficient of the time series JJAS with the time series JASO, etc.

\section{h. Discussion}

Figure 8 is a schematic illustrating the dominant relationships between anomalies in the surface energy fluxes, wind speed, cloudiness, and SST found in our covariance analysis. In Fig. 8, the energy flux at the ocean surface is divided into positive (into the mixed layer) and negative (out of the mixed layer) components. The positive component includes shortwave and downward longwave energy fluxes. The negative component includes latent, sensible, and upward longwave fluxes. Wind speed and cloud amount are also shown schematically.

Figure 8a illustrates the climatological mean state. Latent heat flux dominates the energy out of the mixed layer and is determined to a large extent by the wind speed. Shortwave energy flux (or solar flux) dominates the energy into the mixed layer and is determined to a large extent by cloud amount.

The case in which a positive anomaly in wind speed causes increased evaporation at the surface and, therefore, a negative anomaly in latent heat flux is illustrated in Fig. 8b. ${ }^{6}$ The net loss of energy from the mixed layer due to the negative anomaly in latent heating leads to a negative anomaly in SST. [Analogous to the case shown in Fig. 8b, a negative anomaly in wind speed would cause a positive anomaly in latent heat flux (corresponding to decreased evaporation) and leads to a positive anomaly in SST].

The negative anomaly in SST-tendency caused by the energy imbalance shown in Fig. $8 \mathrm{~b}$ leads to the negative

\footnotetext{
${ }^{6}$ The importance of wind speed in determining latent heating variability is discussed in section $3 \mathrm{~b}$.
} 

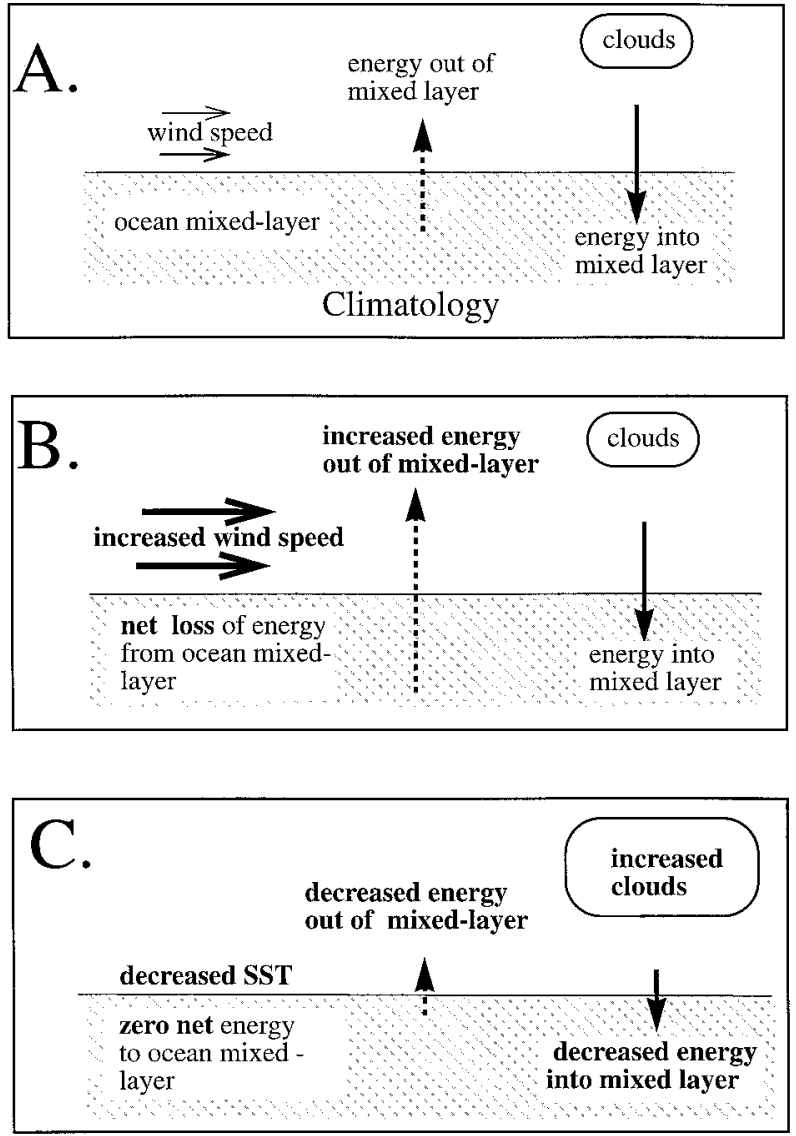

FIG. 8. Schematic illustrating the relationships between the surface energy fluxes, wind speed, and SST. Panel (a) shows the climatological mean state. Panel (b) illustrates the yearround importance of wind speed in determining the energy balance at the surface; increased wind speed causes an anomalous increase in evaporation (and thus a negative anomaly in latent heating). The net loss of energy from the mixed layer leads to a negative anomaly in $\mathrm{SST}^{\prime}$. Panel (c) illustrates the relationship between the summertime (negative) SST anomaly and the surface energy fluxes. The static stability of the lower troposphere increases in the presence of negative $\mathrm{SST}^{\prime}$, and a positive anomaly in cloud amount (and thus negative $Q_{s w}^{\prime}$ ) occurs However, negative $\mathrm{SST}^{\prime}$ is associated with positive $Q_{s h}^{\prime}, Q_{l w}^{\prime}$, and $Q_{l h}^{\prime}$, and the effect of negative $\mathrm{SST}^{\prime}$ on the net surface energy flux anomaly is minimized because $Q_{s w}^{\prime}$ is cancelled by the sum of $Q_{l h}^{\prime}$, $Q_{l w}^{\prime}$ and $Q_{s h}^{\prime}$

anomaly in SST and the anomalies in surface energy fluxes shown in Fig. 8c. In Fig. 8c, the negative anomaly in SST is associated with increased clouds because the lower-tropospheric stability has increased (Klein and Hartmann 1993); the positive anomaly in cloud amount causes a negative downward anomaly in shortwave flux. The negative anomaly in SST is also associated with positive anomalies in latent heat flux (less evaporation) and longwave flux (less longwave is given off by the ocean surface, and more is radiated downward by the clouds). Therefore, several components of the energy flux across the atmosphere-ocean boundary are altered due to the SST variability, but there is close to zero net anomalous energy flux caused by the anomalous SST.
Figures $8 b$ and $8 c$ illustrate the effect of a negative SST anomaly, but the analogous processes are associated with positive $\mathrm{SST}^{\prime}$ : a decrease in wind speed leads to net positive heat flux (B). The ensuing warm water anomaly leads to a further rearrangement of the surface fluxes (C) (with opposite sign) though the rearrangement has a very small net surface flux anomaly and thus does not further affect SST.

\section{Modeling the oceanic mixed layer at OWS $\mathrm{N}$}

\section{a. Model description}

In the subtropical and midlatitude Pacific the deep ocean does not affect surface processes with timescales shorter than about one decade (Gaspar 1988). Thus, the scope of investigations on interannual midlatitude and subtropical air-sea interaction in the Pacific may be confined to the atmosphere and the upper layer of the ocean (Gill and Niiler 1983). In order to test the extent to which the surface energy fluxes are responsible for SST anomaly evolution, a one-dimensional mixed layer model developed by Alexander (1990) is used to simulate the response of the upper ocean to atmospheric forcing at OWS N. The model is designed to study the influence of atmospheric forcing and entrainment on sea surface temperature. The version used in this study is described in detail in Battisti et al. (1995). The temperature of the model's mixed layer, $T_{m}$, is determined by vertical processes, including surface energy fluxes, penetrating solar radiation, entrainment of water from below the mixed layer, convection, and diffusion. The mixed layer is coupled to a convective-diffusive model of the water column below the mixed layer. The model's mixed layer depth, $H$, is determined according to the formulation by Gaspar (1988) and is dependent on the surface buoyancy forcing, wind stress, penetrating solar radiation, and the density discontinuity at the base of the mixed layer. The model has 30 unequally spaced layers between the surface and $1000 \mathrm{~m}$. The first 13 layers are within the first $100 \mathrm{~m}$, giving better resolution near the surface. The time step of the model is one day.

\section{b. Correction flux}

The model's ability to reproduce observed mean seasonal cycle of SST depends on the formulation of a "correction flux," $Q_{\text {cor }}$ (Alexander 1990). Here $Q_{c o r}$ simulates the annual cycle of neglected physics (for example, horizontal advection); $Q_{c o r}$ also corrects for systematic errors in the formulation of the surface fluxes. The correction flux is calculated by forcing the model with the observed daily averaged variables at OWS N, then, at each time step, calculating the energy flux necessary to make the model's mixed layer temperature be equal to the observed SST. This energy is calculated using the model's estimate of mixed layer depth: 


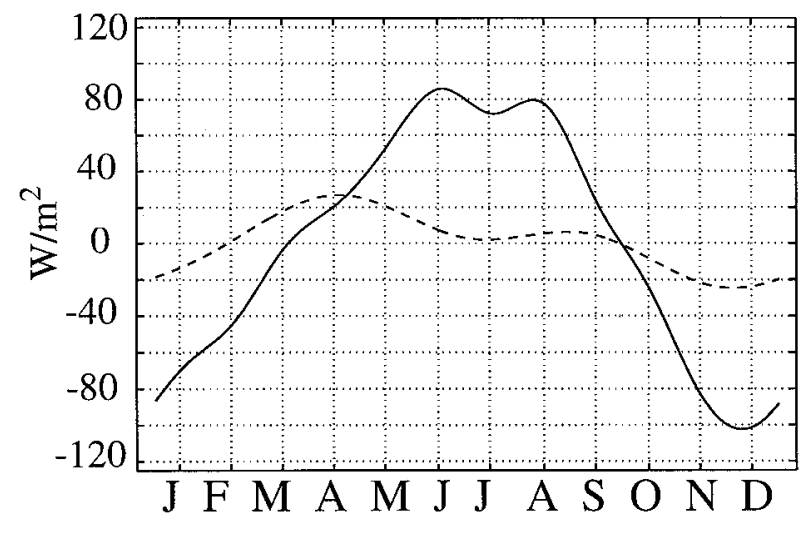

Fig. 9. Annual cycle of $Q_{\text {cor }}$ (dashed line) and the total surface flux (solid line); both have an annual mean of about $1 \mathrm{~W} \mathrm{~m}^{-2}$.

$$
Q_{c o r}=C_{p} \rho H \frac{\left(\mathrm{SST}-T_{m}\right)}{\Delta t}
$$

where $C_{p}$ is the heat capacity of seawater, $\rho$ the density of seawater, $H$ the mixed layer depth, and $\Delta t=1$ day. The model's mixed layer temperature is then set equal to the observed SST, and the model is time-stepped forward. A time series of daily correction fluxes is generated in this fashion as the model is run for the years 1961-72 (excluding 1963, as discussed previously). An annual cycle of this time series may then be made using one of many somewhat arbitrary methods, for example, by creating a 365-day cubic spline of the monthly mean $Q_{\text {cor }}$ or by obtaining an average of each day of the year. The results from all of these methods of calculating $Q_{c o r}$ are very similar. A small constant correction flux is also added to $Q_{\text {cor }}$ to compensate for drift in the model when run for many (e.g., 50) years. The constant term is found by trial and error, repeatedly integrating the model for 55 years to find the constant term that is needed to eliminate drift in $T_{m}$ over that time period.

For reference, the annual cycle of the total surface heat flux and the cyclic $Q_{c o r}$ used in the model experiments is shown in Fig. 9. The annual cycle of the total surface energy flux is generated by splining the monthly averages of the surface energy flux to 365 days. The annual means of $Q_{\text {cor }}$ and the net surface energy flux are both about $1 \mathrm{~W} \mathrm{~m}^{-2}$. These values are consistent with a mean $\left(-2 \mathrm{~W} \mathrm{~m}^{-2}\right)$ due to diffusion of heat through the base of the model.

Subsequent integrations of the model are forced with this cyclically prescribed $Q_{\text {cor }}$ plus the fluxes calculated using the bulk formulas calculated using the observed atmospheric properties and either (i) the simulated mixed layer temperature, $T_{m}$, or (ii) the observed SST. When the surface energy fluxes are calculated with the observed SST, the correction flux estimates that lead to reasonable agreement between $T_{m}^{\prime}$ and $\mathrm{SST}^{\prime}$ for the years 1960-72 lead to model drift when the model is used to simulate the $\mathrm{SST}^{\prime}$ in the years 1955-60. Similarly, cor- rection flux estimates calculated using the years 195560 do not eliminate the model drift when the model is used to simulate the years 1961-72 (1963 is omitted). As mentioned in section 2, the apparent annual cycle of the energy flux is different before and after about 1960 (Dorman et al. 1974). The following discussion refers to the model's response when forced with daily fluxes and the annual cycle $Q_{\text {cor }}$ calculated for the years 1961-72 (except 1963).

\section{c. Model experiments}

Hereafter, model experiments in which the surface energy fluxes are calculated using the bulk formulas and the atmospheric variables with the observed SST are referred to as one-way forced. In the one-way-forced model, the heat fluxes into the mixed layer are independent of the model's response. Model experiments in which the surface energy fluxes are calculated using observed atmospheric variables and the model's mixed layer temperature are referred to as partially coupled.

The partially coupled model experiences negative feedbacks due to infrared cooling and latent and sensible heat fluxes (which depend on the simulated surface temperature) that constrain the model to remain close to the observed air temperature and thus the observed SST (see, e.g., Alexander and Deser 1995). In this way, the model may reproduce the observed SST well without necessarily reproducing mixed layer physics well. In contrast, running the model in the one-way-forced mode is a more rigorous test of the accuracy of the energy flux parameterizations and the mixed layer physics because there are no constraints on the model due to negative feedbacks. However, without negative feedbacks, small errors in the estimate of the net surface energy flux integrated over a long time will result in large errors in $T_{m}$, with maximum error amplification at lower frequencies due to the integration of many small randomly distributed errors over time (see, e.g., Hasselmann 1976).

When the model is run in the one-way-forced mode, the correlation coefficient between the monthly mean simulated sea surface temperature anomaly, $T_{m}^{\prime}$, and the observed $\mathrm{SST}^{\prime}$ is 0.52 . Thus, the the one-way-forced model explains about $27 \%$ of the variance in the $\mathrm{SST}^{\prime}$ : averaged over the summer (winter) months, the model explains $40 \%(3 \%)$ of the variance in $\mathrm{SST}^{\prime}$. When the model is run in the partially coupled mode, the correlation between $T_{m}^{\prime}$ and $\mathrm{SST}^{\prime}$ is 0.86; (explaining about $74 \%$ of the variance in $\mathrm{SST}^{\prime}$ ). The standard deviation of the observed $\mathrm{SST}^{\prime}$ is $0.56^{\circ} \mathrm{C}$; the standard deviations of $T_{m}^{\prime}$ for the one-way-forced and partially coupled runs are $0.78^{\circ} \mathrm{C}$ and $0.52^{\circ} \mathrm{C}$, respectively. Thus, one-wayforced model produces more variability in $T_{m}^{\prime}$ than is observed in $\mathrm{SST}^{\prime}$. Together these results are consistent with the above discussion comparing one-way-forced and partially coupled model runs. The power spectra of the observed $\mathrm{SST}^{\prime}$ and of the $T_{m}^{\prime}$ generated from the 


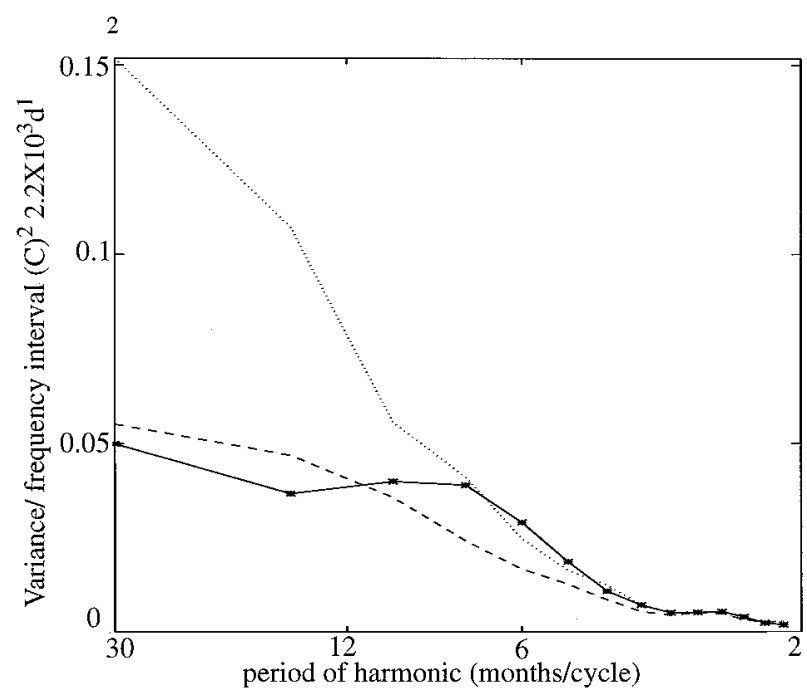

FIG. 10. Power spectra of $\mathrm{SST}^{\prime}$ (solid line with stars), $T_{m}^{\prime}$ from oneway-forced integration (dotted line), and $T_{m}^{\prime}$ from the partially coupled integration (dashed line). Power spectra are calculated using the monthly anomalies of the data (132 data points); 15 spectral estimates are made.

one-way-forced and partially coupled runs are shown in Fig. 10. The spectra are made using monthly anomalies of the data. The power spectrum of the $T_{m}^{\prime}$ generated with the one-way-forced model run has more low-frequency variability than the observed $\mathrm{SST}^{\prime}$ or the $T_{m}^{\prime}$ generated with the partially coupled run. The lack of constraints on the one-way-forced model allows it to respond energetically at very low frequencies to the forcing by the atmosphere, thus producing a "redder" spectrum than in the partially coupled case or than in the observed SST. Next we address this problem.

The model simulates the high-frequency $\mathrm{SST}^{\prime}$ much better than the low-frequency SST'. When the observed $\mathrm{SST}^{\prime}$ and the $T_{m}^{\prime}$ from the one-way-forced run are highpass filtered [using a filter with a Gaussian $e$-folding width of (432 days $)^{-1}$, the correlation coefficient between these time series increases to 0.72 (compared to 0.52 , the correlation coefficient between the unfiltered $\mathrm{SST}^{\prime}$ and unfiltered one-way-forced $T_{m}^{\prime}$ ). The high-pass data are shown in Fig. 11. The high-pass data has less variability than the original data for frequencies less than about (200 days $)^{-1}$; for frequencies higher than this the high-pass data are essentially the same as the original data. The low-pass $\mathrm{SST}^{\prime}$ and one-way-forced $T_{m}^{\prime}$ are not significantly correlated (but see section 4e).

The correlation coefficients between $T_{m}^{\prime}$ and $\mathrm{SST}^{\prime}$ for each month of the year are shown in Fig. 12. The correlation coefficients by month between the high-pass $\mathrm{SST}^{\prime}$ and one-way-forced $T_{m}^{\prime}$ are also shown in Fig. 12. These correlation coefficients are higher than those between unfiltered $\mathrm{SST}^{\prime}$ and the unfiltered one-way-forced $T_{m}^{\prime}$. The difference is especially noticeable in the winter; the wintertime correlation coefficients between $\mathrm{SST}^{\prime}$ and the unfiltered one-way-forced $T_{m}^{\prime}$ (about 0.1 ) are not

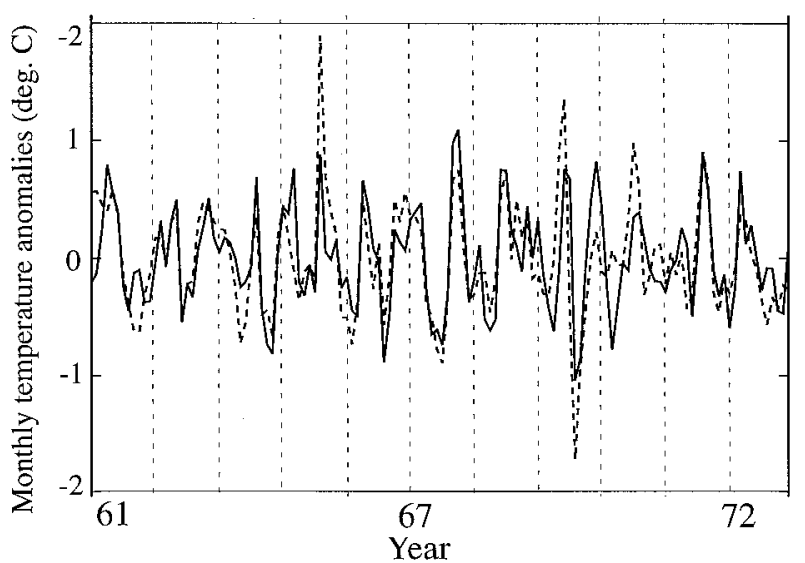

FIG. 11. High-pass-filtered SST' (solid) and one-way-forced model's $T_{m}^{\prime}$ (dashed). The correlation coefficient between the time series is 0.72 . Tick marks are on every January.

significant, but the correlation coefficients between the high-pass-filtered $\mathrm{SST}^{\prime}$ and the one-way-forced $T_{m}^{\prime}$ (about 0.5 ) are statistically significant.

In summary, the model captures about $52 \%$ of the observed variance on timescales from weeks to about one year. At lower frequencies, however, the skill of the model breaks down. The breakdown in model skill could be due to neglected physics (e.g., subsurface advection; see Deser et al. 1996) or errors in the model, or the lack of skill could be due to errors in the estimates of the observed net surface flux. These errors in the estimate of the surface energy flux cause errors in the simulated $T_{m}^{\prime}$ that amplify by integration over time and cause lowfrequency drift in the model.

\section{d. Processes that affect SST at OWS N}

The terms contributing to the evolution of $T_{m}$ are examined to gain insight into the mechanisms controling

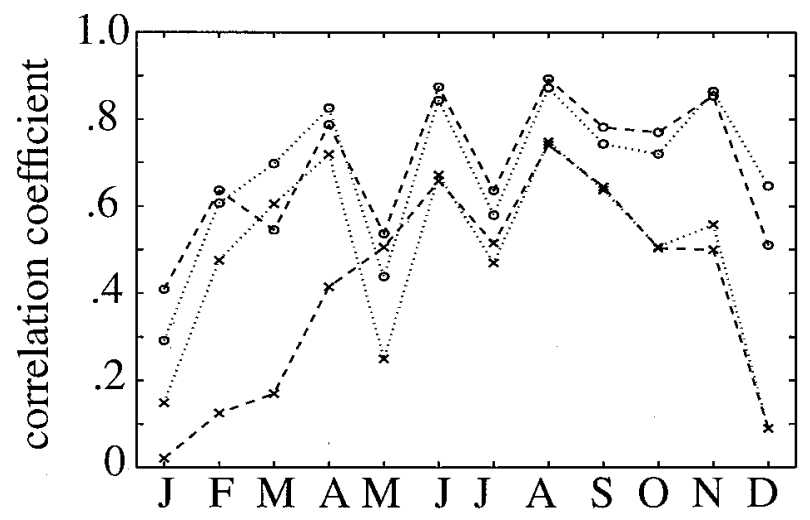

FIG. 12. Each month's correlation coefficient between monthly anomalies of $\mathrm{SST}^{\prime}$ and $T_{m}$. The correlations for the complete data are indicated with $\times \mathrm{s}(\cdots \times \cdots$ advection included; $--\times--$ advection not included); the high-pass data are indicated with the open circles ( $\cdots \bigcirc \cdots$ advection included; $--\bigcirc--$ advection not included). For the high-pass data, there are no significant differences between runs in which advection is included and runs in which it is not. 
$\mathrm{SST}^{\prime}$. The anomalies in the energy fluxes into the mixed layer that have the largest variances are (in decreasing order)

1) total surface energy flux $\left(Q_{n e t}^{\prime}\right)$;

2) heat flux due to entrainment of water from below the mixed layer $\left(Q_{w e}^{\prime}\right)$

3 ) penetrating solar radiation out of the base of the mixed layer;

4) heat flux due to wind-induced Ekman advection. ${ }^{7}$

The standard-deviation of $Q_{n e t}^{\prime}$ is about $30 \mathrm{~W} \mathrm{~m}^{-2}$; it is slightly lower in summer $\sim 24 \mathrm{~W} \mathrm{~m}^{-2}$ and slightly higher in winter $\sim 35 \mathrm{~W} \mathrm{~m}^{-2}$ (see Table 1 ). The standard deviation of the anomalous entrainment energy, $Q_{w e}^{\prime}$, is about $7 \mathrm{~W} \mathrm{~m}^{-2}$ and has a fairly constant seasonal cycle (not shown). Thus, anomalous entrainment contributes only about $7 \%$ of the variance in energy to the mixed layer as does the anomalous net surface heat flux, $Q_{\text {net }}^{\prime}$. Entrainment decreases the heat content of the mixed layer and therefore $Q_{w e}$ is always negative. Anomalous positive $Q_{w e}^{\prime}$ is associated with a decrease in entrainment. The correlation coefficient between $Q_{w e}^{\prime}$ and $Q_{n e t}^{\prime}$ is 0.48 (significant at the $99 \%$ level) and is relatively insensitive to the time of year. We note that reinforcement of the surface flux anomalies by the entrainment flux anomalies is also found in the subtropical Atlantic (Battisti et al. 1995), though at higher latitudes the relationship between these energy sources to the mixed layer is more complicated [see, e.g., Alexander and Deser (1995) for OWS P in the North Pacific and Battisti et al. (1995) for the subpolar North Atlantic].

Finally, although the standard deviation of $Q_{s w}^{\prime}$ increases in the summer, the model simulations indicate that the amount of anomalous net solar radiation $a b$ sorbed by the mixed layer remains about the same all year round (about $7 \mathrm{~W} \mathrm{~m}^{-2}$ ) because a greater portion of the surface energy is deposited below the shallow mixed layer in summer than in winter (Ronca 1995).

\section{e. Ocean advection}

Gill and Niiler (1983) argue that the important energy fluxes for the upper ocean are local energy exchanges at the air-sea interface and that horizontal advection plays a secondary role. The validity of this hypothesis is evaluated for OWS N.

An estimate of the importance of advection to $\mathrm{SST}^{\prime}$ can be made by assuming the force on the mixed layer due to wind stress is balanced by the Coriolis force (i.e., the change in the horizontal pressure gradient is neglected) and there is no stress at the base of the mixed

\footnotetext{
${ }^{7}$ The ranking of the flux terms is based on observations for $Q_{n e}^{\prime}$ and advection and on model results for $Q_{w e}^{\prime}$ and penetrating solar radiation.
}

layer. Integration of the balanced momentum equations over the mixed layer under these assumptions yields

$$
-f[v] H=(1 / \rho)\left(X_{0}\right),
$$

and

$$
f[u] H=(1 / \rho)\left(Y_{0}\right) .
$$

In Eq. (6), $[v]$ and $[u]$ are the depth-averaged northward and eastward velocity components in the mixed layer due to Ekman transport integrated over the mixed layer, $H$ is the mixed layer depth, $X_{0}$ and $Y_{0}$ are the surface wind stress components, and $f$ is the Coriolis parameter. Terms $X_{0}$ and $Y_{0}$ are calculated using the parameterization in Gill (1982), with the transfer coefficient, $C_{d}$, dependent on wind speed according to Isemer and Hasse (1987). Assuming the oceanic advection is due to Ekman transport and the mixed layer depth is uniform, the local change in temperature due to advection may be approximately expressed as

$$
\left(\frac{\partial}{\partial t} \mathrm{SST}\right)_{\text {due to Ekman advection }} \approx-[u] \frac{\partial}{\partial x} \mathrm{SST}+[v] \frac{\partial}{\partial y} \mathrm{SST} .
$$

Thus, the energy flux into the mixed layer due to Ekman advection, $Q_{a d v}$, is approximately

$$
Q_{a d v} \approx \frac{C_{P}}{f}\left(Y_{0} \frac{\partial}{\partial x} \mathrm{SST}+X_{0} \frac{\partial}{\partial y} \mathrm{SST}\right) .
$$

Terms $X_{0}$ and $Y_{0}$ are calculated using observed daily winds at OWS N. To further simplify the estimate of $Q_{a d v}$, SST gradients in Eq. (7) are approximated by their monthly climatological means. The SST are from the COADS (Comprehensive Ocean and Atmosphere Data Set; Woodruff et al. 1987). Thus, the estimate of the heat flux due to wind-induced Ekman transport used in the mixed layer model is

$$
Q_{a d v} \approx \frac{C_{p}}{f}\left(-Y_{0} \frac{\partial}{\partial x}\{\mathrm{SST}\}+X_{0} \frac{\partial}{\partial y}\{\mathrm{SST}\}\right),
$$

where $\{\cdot\}$ denotes the annual cycle. ${ }^{8}$ The variance of monthly $Q_{a d v}^{\prime}$ is $\sim 221 \mathrm{~W}^{2} \mathrm{~m}^{-4}$ annually, $\sim 34 \mathrm{~W}^{2} \mathrm{~m}^{-4}$ in summer (JJASO), and $\sim 457 \mathrm{~W}^{2} \mathrm{~m}^{-4}$ in winter (DJFMA). Thus, in winter $Q_{a d v}^{\prime}$ is comparable to the latent heat flux $Q_{l h}^{\prime}\left(\sim 617 \mathrm{~W}^{2} \mathrm{~m}^{-4}\right)$, and is $40 \%$ of the variance in the net surface heat flux (see Table 1).

When the advective flux [as written in Eq. (8)] is added to the model's net flux input, the result is similar to the anomalous mixed layer temperature in the model when the advective flux is not included: the correlation coefficient between the $T_{m}^{\prime}$ from both simulations is 0.90 .

\footnotetext{
${ }^{8}$ At OWS N, the amplitude of the annual cycle of SST is almost eight times greater than the standard deviation of the anomalies in SST $\left(4.7^{\circ}\right.$ and $0.6^{\circ} \mathrm{C}$, respectively). Thus, neglecting the anomalous SST gradients in the estimate of $Q_{a d v}$ introduces a minor error but is reasonable for the purposes of this study.
} 
The correlation coefficient between observed $\mathrm{SST}^{\prime}$ and $T_{m}^{\prime}$ is 0.55 when oceanic advection is included in the one-way-forced simulation, whereas without oceanic advection the correlation coefficient between the observed SST' and the one-way-forced model's $T_{m}^{\prime}$ is 0.52 . Therefore, including oceanic advection in the model leads to only a modest improvement of the overall skill of the model to hindcast SST' ${ }^{\prime}$. When the low-frequency components [frequencies less than $\sim(200 \text { days })^{-1}$ ] are subtracted from the time series, the correlation coefficient for $\mathrm{SST}^{\prime}$ and $T_{m}^{\prime}$ is $0.71(0.72)$ when advection is (is not) included in the model. Thus, advection is seen to have no significant effect on the high-frequency components of $\mathrm{SST}^{\prime}$.

The correlation coefficients between $T_{m}^{\prime}$ and $\mathrm{SST}^{\prime}$ for each month of the year are shown in Fig. 12. As expected, correlations for each month increase when the data are high-pass filtered. While the addition of windinduced Ekman advection has little impact on the overall skill of the model to forecast $\mathrm{SST}^{\prime}$, Fig. 12 indicates that including advection in the model does significantly increase the skill of the model's forecast of the variability at low frequencies during the late winter (February, March, and April): for all winter months (DJFMA), the correlation coefficient between $T_{m}^{\prime}$ and $\mathrm{SST}^{\prime}$ is $0.45(0.25)$ when advection is (is not) included in the model. During the remaining three-quarters of the year, advection has little or no impact on the skill of the model $\mathrm{SST}^{\prime}$ forecast in either frequency bands. Thus, advective anomalies appear to contribute significantly to the $\mathrm{SST}^{\prime}$ variability at OWS $\mathrm{N}$ only at very low frequencies during wintertime. ${ }^{9}$

\section{Conclusions and discussion}

The major conclusions from this work regarding anomalies in air-sea interaction and sea surface temperature (SST) at OWS $\mathrm{N}$ are summarized below.

- The surface energy flux anomalies are responsible for more than $50 \%$ of the variability of observed monthly SST anomalies (throughout the year).

- The anomalies in latent heating $\left(Q_{l h}^{\prime}\right)$ contribute the most to variability in the net surface heat flux, and variability in wind speed is responsible for most (67\%) of the variability in $Q_{l h}^{\prime}$.

- Wind speed (and therefore $Q_{l h}^{\prime}$ ) has a significant peak in variance centered near 80-days.

- The summer surface energy flux anomalies may be divided into two modes, which are nearly orthogonal. The first mode is defined by the combination of surface fluxes that optimally covary with the $\partial \mathrm{SST}^{\prime} / \partial t$; it describes about $74 \%$ of the combined variance in

\footnotetext{
${ }^{9}$ This result is consistent with Miller et al. (1994), who found that advection was important during the wintertime of the 1976-77 "climate shift"' in the central Pacific Ocean.
}

all of the surface energy flux anomalies. The second mode is defined as the combination of surface fluxes that optimally covary with $\mathrm{SST}^{\prime}$ and describes the remaining $26 \%$ of the variance of all of the surface energy flux anomalies. The first mode is dominated by the latent heat flux term, while the second mode contains significant contributions from the solar, latent, and longwave surface flux. The first mode accounts for fully $96 \%$ of the variance in the net surface heat flux in summer. The time series (principal component) associated with the two modes in the surface energy flux are nearly orthogonal. The first mode dominates the forcing of the ocean by the atmosphere, primarily through wind speed anomalies that alter the latent heat flux.

- The second mode is shown to be the forcing of the atmosphere by the ocean, primarily resulting in a modulation of the cloudiness. The net flux that is associated with the anomalous SST (the second mode) is negligible because the anomalies in "latent plus longwave" heat fluxes largely cancel the anomaly in downward solar flux (positive latent and longwave and negative solar fluxes are associated with negative $\mathrm{SST}^{\prime}$ ). Thus, this mode represents changes in the atmosphere that are forced by changes in SST and the changes in surface fluxes have little feedback on the ocean.

- The flux anomalies that are a result of summertime SST variability (the second mode) are significantly correlated (at one month lag) with the fluxes that force summertime SST anomalies (the first mode); this indicates that the anomalies in SST that force the changes (i.e., force the second mode) in the atmosphere are themselves forced by anomalous surface energy fluxes (primarily wind-induced latent heat anomalies) one month earlier.

- Simulations of the SST using the observed surface fluxes to force a mixed layer ocean model indicate entrainment anomalies generally act in concert with the net surface flux anomalies, but the variance in entrainment flux is small $(\approx 7 \%)$ compared to the net surface heat flux.

- Wind-induced anomalies in ocean advection appear to contribute significantly to the SST anomalies at OWS $\mathrm{N}$ only at very low frequencies during wintertime.

It is interesting to note that Klein et al. (1995) showed that in the region of OWS N, low-cloud amount is better (negatively) correlated with SST 24-30 h upwind than with the local SST; this supports the hypothesis that much of cloud amount variability is forced through changes in SST and the atmosphere responds on relatively rapid timescales (about one day).

Norris and Leovy (1994) suggest that in regions of cold air advection, such as OWS N, cloudiness is maintained in part by latent heat anomalies. More evaporation leads to more cloudiness, which decreases the solar 
forcing, and thus shortwave and latent heating anomalies (positive is heat into the ocean) are positively (but weakly) correlated (see Table 1). However, we find $Q_{s w}^{\prime}$ is better correlated with $\mathrm{SST}^{\prime}$ than with $\partial \mathrm{SST}^{\prime} / \partial t$ in the summer (see Table 3), suggesting that $Q_{s w}^{\prime}$ responds to $\mathrm{SST}^{\prime}$ more than it forces $\mathrm{SST}^{\prime}$. Furthermore, in the summer, the pattern of energy flux variability that covaries with $\mathrm{SST}^{\prime}$ shows that $Q_{s w}^{\prime}$ is of the opposite sense to the other fluxes.

While it is well known that the variance in the net surface heat flux in the subtropics is dominated by the variance in the latent heat flux, our results indicate that variability in the wind speed explains much of the variance in the latent (and net) surface heat flux [Carton et al. (1996) have reached the same conclusion in their study of the tropical Atlantic SST variability]. Finally, we find at OWS $\mathrm{N}$ a significant portion of the variance in the $\mathrm{SST}^{\prime}$ is explained by variability in the surface latent heat flux anomalies. Furthermore, because in the summertime this region is characterized by marine stratus clouds and a strong inversion, these SST anomalies, in turn, force changes in the atmospheric boundary layer, including a change in the low-level cloud amount and in the individual surface flux components. It is possible that our results are specific to OWS N. It will be interesting to examine each of the subtropical stratus regions to determine whether similar forcing of the lower atmosphere by the ocean is a ubiquitous feature of the summertime climate variability in the eastern subtropical oceans.

Acknowledgments. We thank M. Alexander for the use of his mixed layer model used in section 4 and for discussions throughout the course of this work. We thank M. Alexander, C. Bretherton, S. Klein, C. Leovy, A. Miller, and J. Norris for many useful comments on the manuscript.

This research was funded by a grant from the NOAA Office of Global Programs.

\section{REFERENCES}

Alexander, M. A., 1990: Interactions between the north Pacific Ocean and the northern hemisphere atmosphere during El Niño. Ph.D. thesis, University of Wisconsin-Madison, $150 \mathrm{pp}$.

_ 1992 : Midlatitude atmosphere-ocean interaction during E1 Niño. Part I: The North Pacific Ocean. J. Climate, 5, 944-958.

— , and C. Deser, 1995: A mechanism for the recurrence of wintertime midlatitude SST anomalies. J. Phys. Oceanogr., 25, 122 137.

Barsugli, J., 1995: Idealized models of intrinsic midlatitude atmosphere-ocean interaction. Ph.D. thesis, University of Washington, $189 \mathrm{pp}$.

Battisti, D. S., U. S. Bhatt, and M. A. Alexander, 1995: A modeling study of the interannual variability in the wintertime North Atlantic Ocean. J. Climate, 8, 3067-3083.

Carton, J. A., X. Cao, B. Giese, and A. M. Silva, 1996: Decadal and interannual SST variability in the tropical Atlantic Ocean. $J$. Phys. Oceanogr., 26, 1165-1175.

Cayan, D. R., 1992: Latent and sensible heat flux anomalies over the northern oceans: Driving the sea surface temperature. J. Phys. Oceanogr., 22, 859-881.

Clark, N. E., 1972: Specification of sea surface temperature anomaly patterns in the eastern North Pacific. J. Phys. Oceanogr., 2, 391404.

Davis, R. E., 1976: Predictability of sea surface temperature and sea level pressure anomalies over the North Pacific Ocean. J. Phys. Oceanogr., 6, 249-266.

Delworth, T. L., 1996: North Atlantic interannual variability in a coupled ocean-atmosphere model. J. Climate, 9, 2356-2375.

Deser, C., M. A. Alexander, and M. Timlin, 1996: Upper-ocean thermal variations in the North Pacific during 1970-1991. J. Climate, 9, 1890-1855.

Dorman, C. E., C. A. Paulson, and W. H. Quinn, 1974: An analysis of 20 years of meteorological and oceanographic data from Ocean Weather Station N. J. Phys. Oceanogr., 4, 645-653.

Esbensen, S. K., and R. W. Reynolds, 1981: Estimating monthly averaged air-sea transfers of heat and momentum using the bulk aerodynamic method. J. Phys. Oceanogr., 21, 457-465.

Frankignoul, C., 1985: Sea surface temperature anomalies, planetary waves, and air-sea feedback in the middle latitudes. Rev. Geophys., 23, 357-390.

— midlatitude sea surface temperature anomalies. J. Phys. Oceanogr., 13, 1131-1145.

Gaspar, P., 1988: Modeling the seasonal cycle of the upper ocean. $J$. Phys. Oceanogr., 18, 161-180.

Gill, A. E., 1982: Atmosphere-Ocean Dynamics. Academic Press, $662 \mathrm{pp}$.

- and P. P. Niiler, 1983: The theory of the seasonal variability in the ocean. Deep-Sea Res., 20, 141-177.

Gilman, D. L., F. J. Fuglister, and J. M. Mitchell, 1963: On the power spectrum of red noise. J. Atmos. Sci., 20, 182-184.

Goerss, J. S., and C. E. Duchon, 1980: Effect of ship heating on drybulb temperature measurements in GATE. J. Phys. Oceanogr., 10, 478-479.

Haney, R. L., 1985: Midlatitude sea surface temperature anomalies: A numerical hindcast. J. Phys. Oceanogr., 15, 787-799.

Hasselmann, K., 1976: Stochastic climate models, Part I. Tellus, 28, $473-485$.

Isemer, H.-J., and L. Hasse, 1987: The Bunker Climate Atlas of the North Atlantic Ocean. Springer-Verlag, 252 pp.

Julian, P. R., 1971: Some aspects of variance spectra of synopticscale tropospheric wind components in midlatitudes and in the Tropics. Mon. Wea. Rev., 99, 954-965.

Klein, S. A., and D. L. Hartmann, 1993: The seasonal cycle of low stratiform clouds. J. Climate, 6, 1587-1606.

,-- , and J. R. Norris, 1995: Relationships among low-cloud structure, sea surface temperature, and atmospheric circulation in the summertime northeast Pacific. J. Climate, 8, 11401155.

Kushnir, Y., and N.-C. Lau, 1992: The general circulation model response to a North Pacific SST anomaly: Dependence on timescale and pattern polarity. J. Climate, 5, 271-283.

Large, W. G., and S. Pond, 1982: Sensible and latent heat flux measurements over the ocean. J. Phys. Oceanogr., 12, 464-482.

Lau, N.-C., and M. J. Nath, 1990: A general circulation model study of the atmospheric response to extratropical SST anomalies observed in 1950-79. J. Climate, 3, 965-989.

Leith, C. E., 1973: The standard error of time-average estimates of climatic means. J. Appl. Meteor. 12, 1066-1069.

Liu, W. T., K. B. Katsaros, and J. A. Businger, 1979: Bulk parameterization of air-sea exchanges of heat and water vapor including the molecular constraints. J. Atmos. Sci., 36, 1722-1735.

Luksch, U., and H. von Storch, 1992: Modeling the low-frequency sea surface temperature variability in the North Pacific. J. Climate, 5, 893-906.

Miller, A., D. R. Cayan, T. P. Barnett, N. E. Graham, and J. M. Oberhuber, 1994: Interdecadal variability of the Pacific Ocean: 
Model response to observed heat flux and wind stress anomalies. Climate Dyn., 9, 287-302.

Miller, A. J., 1992: Large-scale ocean-atmosphere interactions in a simplified coupled model of the midlatitude wintertime circulation. J. Atmos. Sci., 49, 273-286.

Norris, J. R., and C. R. Leovy, 1994: Interannual variability in stratiform cloudiness and sea surface temperature. J. Climate, 7, 1915-1925.

Peng, S., L. A. Mysak, H. Ritchie, J. Derome, and B. Dugas, 1995: The differences between early and midwinter atmospheric responses to sea surface temperature anomalies in the northwest Atlantic. J. Climate, 8, 139-157.

Reed, R. K., 1977: On estimating insolation over the ocean. J. Phys. Oceanogr., 7, 482-485.

Ronca, R. E., 1995: Processes controlling anomalous sea surface temperature and air-sea energy exchange on intra-annual timescales in the northeastern subtropical Pacific. M.S. thesis, Dept. of Atmospheric Sciences, University of Washington, $90 \mathrm{pp}$.

Sarachik, E. S., 1984: Large-scale surface heat fluxes. Large-scale
Oceanographic Experiments and Satellites, C. Gautler and M. Fieux, Eds., Reidel, 147-167.

Smith, S., and F. Dobson, 1984: The heat budget at Ocean Weather Station Bravo. Atmos. Ocean, 22, 1-22.

Wallace, J. M., and Q. Jiang, 1987: On the observed structure of the interannual variability of the atmosphere/ocean climate system. Atmospheric and Oceanic Variability, H. Cattle, Ed., Roy. Meteor. Soc., 17-43.

- C. Smith, and Q. Jiang, 1990: Spatial patterns of atmosphereocean interaction in the northern winter. J. Climate, 3, 990-998.

Weare, B. C., 1989: Uncertainties in estimates of surface heat fluxes derived from marine reports over the tropical and subtropical oceans. Tellus, 41A, 357-370.

— 1994 : Interrelationships between cloud properties and sea surface temperatures on seasonal and interannual time scales. $J$. Climate, 7, 248-260.

Woodruff, S. D., R. J. Slutz, R. L. Jenne, and P. M. Steurer, 1987: A Comprehensive Ocean-Atmosphere Data Set. Bull. Amer. Meteor. Soc., 68, 1239-1250. 